\title{
EVALUATION OF ANNOYANCE FROM THE WIND TURBINE NOISE: A PILOT STUDY
}

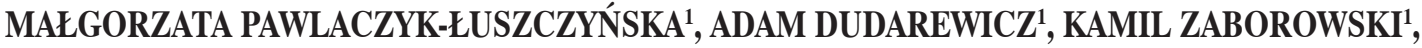 MALGORZATA ZAMOJSKA-DANISZEWSKA ${ }^{1}$, and MALGORZATA WASZKOWSKA ${ }^{2}$}

${ }^{1}$ Nofer Institute of Occupational Medicine, Łódź, Poland

Department of Physical Hazards

${ }^{2}$ Nofer Institute of Occupational Medicine, Łódź, Poland

Department of Occupational Psychology

\begin{abstract}
Objectives: The overall aim of this study was to evaluate the perception of and annoyance due to the noise from wind turbines in populated areas of Poland. Material and Methods: The study group comprised 156 subjects. All subjects were asked to fill in a questionnaire developed to enable evaluation of their living conditions, including prevalence of annoyance due to the noise from wind turbines and the self-assessment of physical health and well-being. In addition, current mental health status of the respondents was assessed using Goldberg General Health Questionnaire GHQ-12. For areas where the respondents lived, A-weighted sound pressure levels (SPLs) were calculated as the sum of the contributions from the wind power plants in the specific area. Results: It has been shown that the wind turbine noise at the calculated A-weighted SPL of 30-48 dB was noticed outdoors by $60.3 \%$ of the respondents. This noise was perceived as annoying outdoors by $33.3 \%$ of the respondents, while indoors by $20.5 \%$ of them. The odds ratio of being annoyed outdoors by the wind turbine noise increased along with increasing SPLs (OR $=2.1 ; 95 \% \mathrm{CI}$ : 1.22-3.62). The subjects' attitude to wind turbines in general and sensitivity to landscape littering was found to have significant impact on the perceived annoyance. About $63 \%$ of variance in outdoors annoyance assessment might be explained by the noise level, general attitude to wind turbines and sensitivity to landscape littering. Conclusions: Before firm conclusions can be drawn further studies are needed, including a larger number of respondents with different living environments (i.e., dissimilar terrain, different urbanization and road traffic intensity).
\end{abstract}

Key words:

Wind turbines, Noise, Health effects, Annoyance

\section{INTRODUCTION}

Community noise is recognized as an environmental stressor, which causes nuisance, decreased well-being and possibly non-auditory adverse effects on health [1]. Wind turbines are relatively new sources of community noise and their impact on people living nearby has not been completely determined yet. Most of the epidemiological evidence on the wind turbine noise comes from the cross-sectional studies carried out in Sweden and in the Netherlands between 2000 and 2007 [2-5].

According to the aforesaid surveys, proportion of people being annoyed by the wind turbine noise increased along with increasing noise levels [2-4]. Generally, people were more likely to be annoyed when A-weighted sound pressure levels exceeded 35-40 dB [3,4]. Subjective factors such as having turbines visible from the dwelling, negative

This study was supported by the Ministry of Science and Higher Education of Poland (Grant IMP 18.5/2011-2012).

Received: October 19, 2012. Accepted: February 17, 2014.

Corresponding author: M. Pawlaczyk-Łuszczyńska, Nofer Institute of Occupational Medicine, Department of Physical Hazards, św. Teresy 8, 91-348 Łódź, Poland (e-mail: mpawlusz@imp.lodz.pl). 
opinion about wind turbines in general and/or their visual impact on landscape, and self-reported sensitivity to noise increased the probability of being annoyed by the wind turbine noise [2,3], while obtaining economic benefits from wind turbines reduced the risk of annoyance [4]. It was also found that terrain and urbanization had impact on the perceived annoyance from the wind turbine noise [3].

In comparison to other European countries, especially the ones where the use of renewable energy sources is advanced, such as Germany, Spain or Denmark, Poland is just at the beginning of its "wind adventure". However, despite the recent and rapid development of wind power, local communities in Poland often oppose to new wind turbine projects. Apart from noise, the main arguments against wind turbines are: littering the landscape and shadow flicker accompanying wind turbines operation. Possible adverse and/or annoying effects of noise, including infrasound and low frequency noise are a source of particular concern. However, data on reactions to wind turbine noise in people living in their vicinity are missing. Therefore, the overall objective of this study was to evaluate the perception of and annoyance due to the noise from wind turbines in populated areas of Poland. In particular, it has been attempted to:

- analyze the annoyance level in relation to the distance from wind turbines and levels of the wind turbine noise at the dwelling,

- explore individual factors affecting the perceived annoyance.

\section{MATERIAL AND METHODS}

A pilot field study on response to the wind turbine noise was carried out in Poland in 2011. The study population consisted of people living in the vicinity of 3 wind farms located in the central and north-western parts of Poland. The survey was performed during May and June, when people were expected to spend time outdoors. Three areas of totaling $132.58 \mathrm{~km}^{2}$ were investigated. Of 108 wind turbines in the selected areas, 42 had a power of $2 \mathrm{MW}, 60$ turbines had a power of $1.5 \mathrm{MW}$ and 6 turbines of $0.15 \mathrm{MW}$. The towers were $95 \mathrm{~m}, 100 \mathrm{~m}$ or $30 \mathrm{~m}$ in height.

A questionnaire was applied as the main research tool. For investigated areas, A-weighted sound pressure levels (SPLs) were calculated as the sum of the contributions from the wind power plants in the neighborhood. In addition, noise conditions outside the dwellings were verified at random by in situ measurements.

\section{Study group}

The study group comprised 156 subjects aged from 15-82 years. They were personally asked to complete the questionnaires. No exclusion criteria were applied. Therefore, each subject who agreed to participate in the study was included in it.

\section{Questionnaires}

The subjects were asked to fill in a questionnaire developed to enable evaluation of their living conditions, including prevalence of annoyance due to noise from wind turbines, and self-assessment of physical health and wellbeing. At least 1 copy of the questionnaire was delivered to each household. The response rate was approx. $71 \%$. Almost all the subjects (91.7\%) completed the questionnaire themselves with the exception of some elderly people who were interviewed.

The questionnaire was based on the one previously used in Swedish studies [2,3] and, like the aforesaid questionnaire, it was constructed in such a way so as to mask the main intention. The responses to majority of the questions were rated on 5-score rating scales.

The questionnaire consisted of 2 parts. The first one comprised inquiries concerning:

1. Housing and satisfaction with the living environment including questions on occurrence ("yes" or "no") and 
the degree of annoyance experienced outdoors and indoors from various nuisances, i.e. odors (from industries, landfills and agriculture) and noises from a variety of sources, e.g. agricultural machinery, hand held and stationary power tools, road traffic, railway, airplanes and wind turbines noise ("not annoying at all", "a little annoying", "rather annoying", "annoying”, or "extremely annoying").

2. Paying attention to noise, odors and air pollution, landscape littering (visual intrusions) ("definitely yes", "yes", "no opinion", "no", or "definitely no").

3. General opinion on (attitude towards) wind turbines and on the visual impact of wind turbines ("very positive", "positive", "no opinion", "negative", or "very negative").

4. Different visual and auditory aspects of wind turbines, such as noise, shadows and reflections from rotor blades, during various subjects' activities (e.g., relaxing, taking walks) and weather conditions.

The second part of the questionnaire was aimed at self-assessment of the subjects' physical health, including hearing status ("very poor", "poor", "rather poor", "rather good", "good", or "very good"). It also comprised questions on:

5. Chronic illnesses, e.g. cardiovascular diseases, hearing impairment, etc. ("yes" or "no").

6. General well-being, i.e. suffering from headaches, undue tiredness, pain and stiffness in the back, neck, and shoulders, felling stressed, irritable ("never" / "almost never", "several times a year", "several times a month", "several times a week", or "everyday" / "almost every day").

7. Quality of sleep, i.e. being refreshed and having difficulty with falling asleep ("never" / "almost never", "several times a year", "several times a month", "several times a week", or "everyday" / "almost every day"), etc. Statistical analysis of the results of this pilot study confirmed the high consistency of questions assessing response to wind turbines by Cronbach's $\alpha$ coefficient equaling 0.93 . In addition, current mental health status of the respondents was assessed using 12-item Goldberg General Health
Questionnaire (GHQ-12), which was adapted for Polish conditions [6,7]. The response rate was approx. 54\%.

This questionnaire was derived from the main version of the Goldberg General Health Questionnaire, which consists of 12 items describing various symptoms of mental health problems related to 2 areas, i.e., inability to carry out one's normal "healthy" functions and the appearance of new phenomena of a distressing nature. The subjects are asked to assess the changes in their mood, feelings and behaviors in the period of recent 4 weeks using a 4-point response scale ("less than usual", "no more than usual", "rather more than usual" and "much more than usual").

Two methods were used for scoring the results of GHQ-12. First of all, responses to each question were coded on the scale from 0 to 3 . The total score per subject was obtained by adding the sores for 12 questions. The more mental disorders reported (number and severity of symptoms), the higher total score of the GHQ-12. In addition, in order to identify the so-called „cases” (i.e., persons with mental health disorders) the GHQ method was applied for the classification. The answers: "less than usual" and "no more than usual" were coded "0" (non-attendance of symptom), and the answers "rather more than usual", "much more than usual" were coded " 1 " (attendance of symptom). In the latter method, the cut-off point between "non-case" and "case" for the total score of the questionnaire was $2 / 3$. So, persons with scores 2 and less were classified as "non-cases" (healthy) while persons with scores 3 or more were classified as "cases" [6,7].

\section{Noise exposure evaluation}

For areas where the respondents lived, A-weighted sound pressure levels (SPLs) were calculated as the sum of the contributions from the wind turbines in the neighborhood based on the sound propagation model described in ISO 9613-2:1996 [8]. 
In these calculations, the A-weighted sound power levels of wind turbines specified by manufactures were used. The arrangement of turbines within each of the farms was taken from the internet maps [9], while the distances between dwellings and turbines were calculated based on the GPS data collected in front of residential premises. The SON2 (version 3.3, Z.U.O "Eko-Soft") software package was applied for noise calculations.

In addition, a correction factor of $+4.7 \mathrm{~dB}$ calculated by van der Berg [10] was added to the predicted A-weighted SPLs to obtain the day-evening-night noise levels $\left(\mathrm{L}_{\mathrm{den}}\right)$.

The calculated A-weighted SPLs were verified at random by in situ measurements. Relatively quiet areas without too many masking noises (e.g., noises from agricultural machines, hand held and stationary power tools or road-traffic noise) were chosen. Consequently, for part $(45.5 \%)$ of the respondents $(\mathrm{N}=71)$, noise levels were measured outside their dwellings at the height of $4 \mathrm{~m}$ in the distance of $3 \mathrm{~m}$ (or more) from the façade. Measuring points were located next to the respondents' houses in such a way that the distance from the nearest turbine was less than the distance between the turbine and the respondent's house.

These measurements were carried out according to the Polish recommendation concerning assessment of environmental noise [11]. Apart from the equivalent-continuous A-weighted SPL $\left(\mathrm{L}_{\text {Aeq, } \mathrm{T}}\right)$, other basic noise parameters, such as: C- and G-weighted sound pressure levels $\left(\mathrm{L}_{\text {Ceq, } \mathrm{T}}\right.$ and $\left.\mathrm{L}_{\mathrm{Geq}, \mathrm{T}}\right)$ were measured. In addition, frequency analysis in $1 / 3$-octave bands from $1.6 \mathrm{~Hz}$ to $20 \mathrm{kHz}$ was carried out.

Noise measurements were performed using a SVANTEK type SVAN 958 sound analyzer (with SVANTEK type SV22L microphone and type SV12L preamplifier) equipped with a windscreen. At each measuring point, at least 5 noise samples, each lasting 1 min, were collected. Particular attention was paid to avoid including masking noises, such as road-traffic noise, dogs' barking, etc.
However, it was impossible to exclude bird singing and insects hum.

Measurements were carried out during the day time. In order to fulfill requirements of the applied reference measuring method [11] the meteorological parameters (i.e., air temperature, humidity, atmospheric pressure, velocity and direction of wind) were simultaneously monitored using a weather station (Technoline type WS 3650 IT).

\section{Data analysis}

To analyze the relationships between the distance from wind turbines and/or levels of the wind turbine noise at the dwelling and the percentage of people annoyed by the noise, the study subjects were classified into subgroups (categories) according to the calculated A-weighted SPL at their dwellings (4 categories, i.e., noise categories of $30-35 \mathrm{~dB}, 35-40 \mathrm{~dB}, 40-45 \mathrm{~dB}$ and $45-50 \mathrm{~dB}$ ) as well as according to the distance of their dwellings from the nearest wind turbine (4 distance categories, i.e., below 400 m, 400-800 m, 800-1200 m, and above 1200 m). To analyze the impact of different subjective variables, the subjects were also divided into subgroups according to: i) age (younger and older subjects), ii) gender (male and female), iii) sensitivity to odors and air pollutions, landscape littering and noise (sensitive and insensitive subjects), iv) attitude toward the wind turbines in general and to the visual impact in particular (negative and positive), v) self-assessment of physical health (negative and positive), and vi) the GHQ-12 score. In the latter case, the subjects were classified in 2 ways, i.e. as subjects with and without mental health disorders (cases and others) as well as high- and low-scored in the GHQ-12 individuals (i.e., scored above and below the median value of 11.0). When relevant, the data from 5-score (or 6-point) verbal rating scales were dichotomized. The answers "rather annoying", "annoying" and "extremely annoying" were classified as "annoying", while other ("not annoying at all" and "a little annoying") as "not annoying". Similarly, 
"very negative" and "negative" attitude towards the wind turbines (in general and to the visual impact in particular) or self-assessment of physical health were categorized as "negative" while other (i.e., "no opinion", "positive" or "very positive") as "positive (not negative)". On the other hand, when analyzing paying attention to various environmental nuisances, the respondents who answered "definitely yes" and "yes" were classified as sensitive to noise, landscape littering or air pollution. A similar method for classification of sensitive subjects was applied in earlier studies [2].

Answers to the questionnaire were presented as the proportions with $95 \%$ confidence intervals in the total study group as well as the proportion of the number of respondents in various subgroups. Differences between the various pairs of subgroups in proportions of answers were evaluated using the exact Fisher test. Mann-Whitney U test was applied to evaluate the differences between various pairs of subgroups in answers on ordinal scale (e.g., females and males answers on the 5-score rating scale).

Relationships between the variables (e.g., noise annoyance assessment and general attitude to wind turbine expressed on 5-score verbal rating scales) were analyzed using Spearman's nonparametric rank correlation coefficient $r_{s}$. Binary logistic regression was used to study the influence of various variables (including noise or distance category and subjective factors) on annoyance related to the wind turbine noise. The Nagelkerke pseudo- $\mathrm{R}^{2}$ was applied as a measure of explained variance [12].

Statistical analysis was performed with an assumed level of significance $p=0.05$. However, when comparing the pairs of various subgroups of respondents or analyzing several relationships at the same time, to avoid the risk of mass significance, $\mathrm{p}$-value divided by the number $(\mathrm{N})$ of possible comparisons or correlations $(\mathrm{p}=0.05 / \mathrm{N})$ was set as the limit for statistical significance. Statistical analyses were carried out using Statistica (version 9.1. StatSoft, Inc.) software package.

\section{RESULTS}

\section{Study group}

Characteristics of the study population given as proportions of the subjects in total, as well as in various noise and distance categories is presented in Table 1 . The most numerous noise categories were the subgroups of subjects exposed to noise of the calculated A-weighted sound pressure levels of $35-40 \mathrm{~dB}(38.5 \%)$ and $40-45 \mathrm{~dB}(50.6 \%)$. On the other hand, when sorting the respondents according to the distance from the nearest wind turbine, the most numerous were subgroups living at the distance of 400-800 m and 800-1200 m, which comprised 62.8\% and $29.5 \%$ of the subjects, respectively.

Generally, majority of the respondents (71.2\%) lived in privately owned detached or semi-detached houses in the countryside or in small villages. The landscape was rather flat and mainly agricultural, but railroads and/or roads were also present. Almost all the respondents (96.8\%) could see 1 or more wind turbines from their dwelling, backyard or garden. Only a few (2.6\%) of them had profits from the wind turbines.

About half $(50.6 \%)$ of the respondents were employed, while $24.4 \%$ of them were pensioners. Of those working, $36.7 \%$ were farmer workers. Majority of the subjects had primary $(26.3 \%)$, vocational $(21.8 \%)$ or secondary (high school) education ( $38.5 \%$ ).

The mean age in the study population was $46.2 \pm 15.8$ years (median value: 48.0 years). Women were more numerous than men ( $60.3 \%$ vs. $39.7 \%)$. However, no statistically significant differences between females and males were found regarding sensitivity to noise (and landscape littering or odors and air pollutions) as well as well-being. Similar relationships were observed for younger (aged $\leq 48$ years) and older (aged $>48$ years) subjects $(\mathrm{p}<0.05)$.

Over half of the subjects were classified as sensitive to noise $(57.7 \%)$, landscape littering (52.6\%), odors and air pollutions (60.3\%). About $1 / 5$ of the respondents declared negative ("very negative" or "negative") attitude 


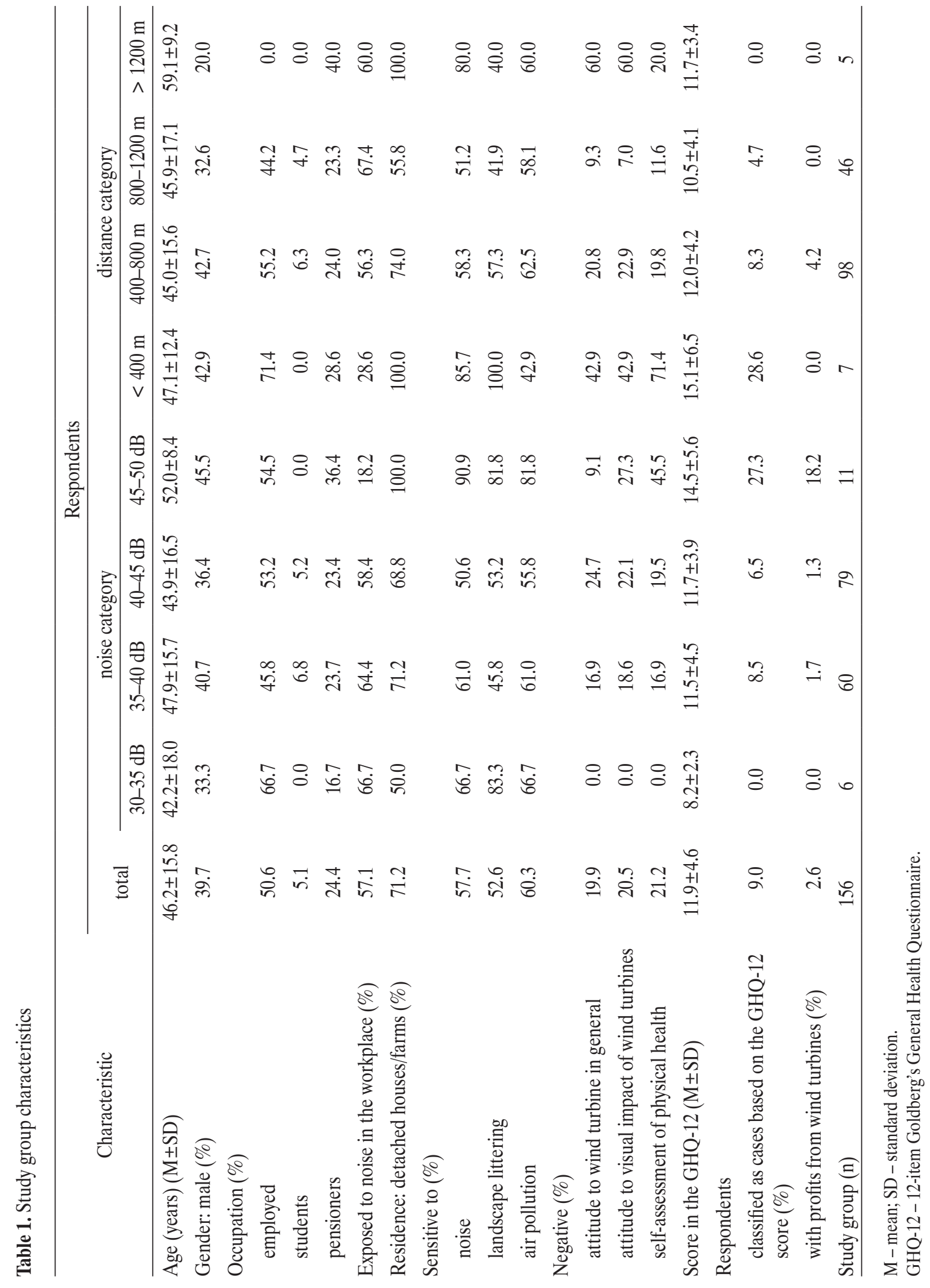


towards wind turbines in general and towards their visual impact in particular. The same fraction of subjects assessed their health status as poor ("poor" or "very poor") (Table 1). A part of them suffered from cardiovascular diseases $(32.7 \%)$, thyroid diseases $(9.6 \%)$ and diseases of nervous system $(12.2 \%)$. Only a few of the respondents $(4.5 \%)$ reported difficulties with hearing normal speech, while $12.2 \%$ of them reported difficulties with understanding speech in noisy environment.

The respondents examined using the GHQ-12 obtained a mean score at the level of $11.9 \pm 4.6$, which was close to the normative result for the reference Polish population $(11.17 \pm 5.11)$ [6]. However, when the GHQ method was used for the scoring, of the total respondents, only $9 \%$ were recognized as cases, i.e., having mental health disorders.

The majority of subjective factors (i.e. sensitivity to various environmental nuisances, attitude to wind turbines, physical and mental health status) were correlated to each other (Table 2). In particular, there was a relatively high positive correlation between general attitude toward wind turbines and attitude to their visual impact in particular (Spearman's rank correlation coefficient $r_{s}=0.81$, $\mathrm{p}<0.000001)$ as well as between the respondents' sensitivity to noise and sensitivity to landscape littering $\left(\mathrm{r}_{\mathrm{s}}=0.61, \mathrm{p}<0.000001\right)$.

\section{Noise exposure evaluation}

Generally, the study subjects lived at the distance from $235 \mathrm{~m}$ to $2470 \mathrm{~m}$ (mean value $(\mathrm{M}) \pm$ standard deviation (SD): $740 \pm 285 \mathrm{~m}$, median (Me): $732 \mathrm{~m}$ ) from the nearest wind turbine. They were exposed to the wind turbine noise at the measured equivalent-continuous:

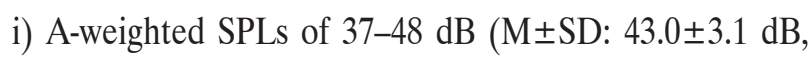
Me: $42.6 \mathrm{~dB}$ ), and ii) C-weighted SPLs of $46-66 \mathrm{~dB}$ $(\mathrm{M} \pm \mathrm{SD}: 58.0 \pm 5.0 \mathrm{~dB}, \mathrm{Me}: 63.0 \mathrm{~dB})$, iii) G-weighted SPLs of $61-90 \mathrm{~dB}(\mathrm{M} \pm \mathrm{SD}: 79.5 \pm 6.5 \mathrm{~dB}, \mathrm{Me}: 81.4 \mathrm{~dB})$. The noise prevailing at the respondents' dwellings included

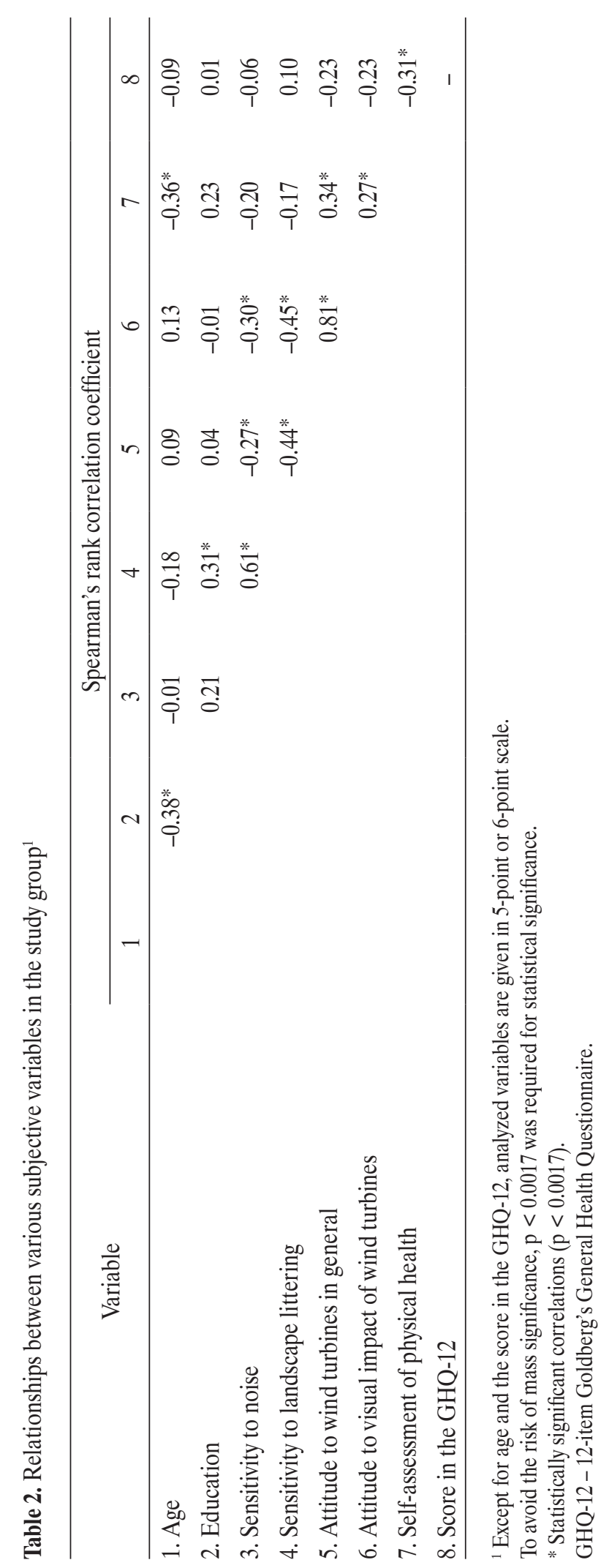




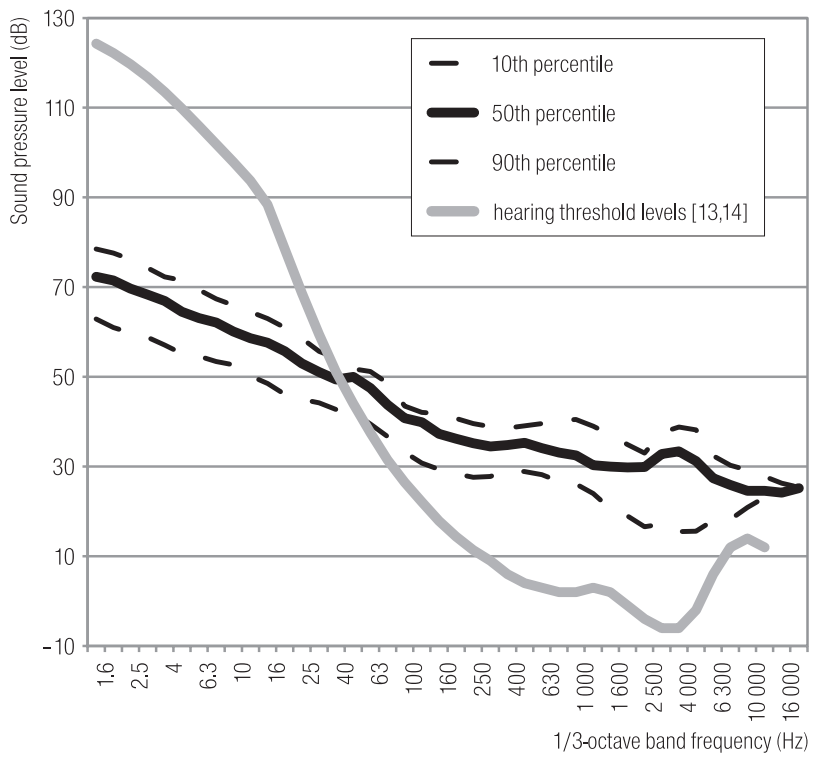

Fig. 1. 1/3-octave band spectra of noise measured outside the respondents' dwellings together with hearing threshold levels

infrasonic components but at levels lower than the relevant hearing threshold levels (Figure 1).

It is worth noting that meteorological parameters during noise measurements fulfilled requirements of the applied measuring method [11]. Air velocity ranged from $0.5 \mathrm{~m} / \mathrm{s}$ to $3.8 \mathrm{~m} / \mathrm{s}$, atmospheric pressure remained within the range of $1002-1028 \mathrm{hPa}$, while relative humidity varied from $35.3 \%$ to $71.1 \%$.

The calculated A-weighted SPL ranged from $30 \mathrm{~dB}$ to $48 \mathrm{~dB}$, while corresponding exposure metrics $\mathrm{L}_{\text {den }}$ varied from $35 \mathrm{db}$ to $53 \mathrm{~dB}$ (Table 3 ). It should be noted that the mean value of difference between calculated and measured A-weighted SPLs outside the respondents' dwellings was $0.7 \mathrm{~dB}(95 \% \mathrm{CI}$ : $-2.6-1.2)$.

\section{Questionnaire survey results}

\section{Main results}

Generally, over a half of the respondents paid attention to the environmental conditions in their place of living such as odors and air pollutions (60.3\%), landscape littering $(52.6 \%)$ and noise from various sources $(57.7 \%)$ (see
Table 1 for percentages of the subjects classified as sensitive to the aforesaid environmental factors).

The most frequently reported nuisances, which were noticed outside the dwellings included: the wind turbine noise $(60.3 \%)$, road traffic noise (55.1\%), noise from agricultural machinery (53.2\%) and hand held, and stationary power tools (48.7\%). But there were no significant differences between the proportion of the subjects noticing (i.e., reporting the occurrence) the wind turbine noise outdoors and the other aforesaid noises. Similar relationships were observed when analyzing the perception of various nuisances indoors (Figure 2). However, the wind turbine noise was significantly more frequently assessed as annoying than other environmental nuisances, including road traffic noise (Figure 3).

Generally, the wind turbine noise was noticed outdoors by $60.3 \%$ of the subjects, while by $39.7 \%$ of them - indoors (Table 4). Moreover, this type of noise was perceived as annoying outdoors (i.e., as "rather annoying", "annoying" or "extremely annoying") by $33.3 \%$ of the respondents. On the other hand, $20.5 \%$ of the subjects said that they were annoyed indoors. However, only a few of the subjects were extremely annoyed by the wind turbine noise outdoors (5.2\%) and indoors (3.3\%) (Figure 4).

Proportion of the subjects who noticed the wind turbine noise outdoors decreased significantly from $65.6 \%$ in distance category of $400-800 \mathrm{~m}$ to $46.5 \%$ in distance category of 800-1200 m (Table 4). The percentage of those perceiving the wind turbine noise indoors also decreased significantly along with a greater distance $(46.9 \%$ at distance of $400-800 \mathrm{~m}$ and $23.3 \%$ at $800-1200 \mathrm{~m}$ ). Similar relationships were observed in the case of the proportions of respondents being annoyed by noise (both outdoors and indoors) but differences between the aforesaid distance categories were not significant.

On the other hand, the proportion of subjects who noticed the wind turbine noise outdoors increased (but not significantly) from $54.2 \%$ in noise category of $35-40 \mathrm{~dB}$ to $61 \%$ in noise category of 40-45 $\mathrm{dB}$ (Table 4). The percentage of 
Table 3. Noise calculations for areas where the respondents lived and the distance from the nearest wind turbine

\begin{tabular}{lcccccc}
\hline \multirow{2}{*}{ Group of respondents } & \multicolumn{2}{c}{$\begin{array}{c}\text { A-weighted sound } \\
\text { pressure level } \\
(\mathrm{dB})\end{array}$} & \multicolumn{2}{c}{$\begin{array}{c}\text { Day-evening-night } \\
\text { noise level }\left(\mathrm{L}_{\mathrm{den}}\right) \\
(\mathrm{dB})\end{array}$} & \multicolumn{2}{c}{$\begin{array}{c}\text { Distance } \\
(\mathrm{m})\end{array}$} \\
\cline { 2 - 7 } & $\mathrm{M} \pm \mathrm{SD}$ & $\mathrm{Me}$ & $\mathrm{M} \pm \mathrm{SD}$ & $\mathrm{Me}$ & $\mathrm{M} \pm \mathrm{SD}$ & $\mathrm{Me}$ \\
\hline $\begin{array}{l}\text { Respondents (total) } \\
\text { Noise category (dB) }\end{array}$ & $41.0 \pm 3.0$ & 40.9 & $45.7 \pm 3.0$ & 45.6 & $739.7 \pm 284.9$ & 732 \\
$30-35$ & $32.9 \pm 2.1$ & 34.2 & $37.6 \pm 2.1$ & 38.9 & $767.8 \pm 186.3$ & 813 \\
$35-40$ & $38.9 \pm 0.8$ & 39.1 & $43.6 \pm 0.8$ & 43.8 & $842.1 \pm 279.7$ & 800 \\
$40-45$ & $42.6 \pm 1.4$ & 42.6 & $47.3 \pm 1.4$ & 47.3 & $694.2 \pm 283.3$ & 640 \\
$45-50$ & $46.0 \pm 1.0$ & 45.7 & $50.7 \pm 1.0$ & 50.4 & $493.0 \pm 83.7$ & 512 \\
Distance category (m) & & & & & & \\
$<400$ & $45.0 \pm 2.4$ & 44.9 & $49.7 \pm 2.4$ & 49.6 & $328.9 \pm 69.1$ & 353 \\
$400-800$ & $41.2 \pm 3.0$ & 41.3 & $45.9 \pm 3.0$ & 46.0 & $629.5 \pm 110.9$ & 612 \\
$800-1200$ & $39.9 \pm 2.4$ & 39.4 & $44.6 \pm 2.4$ & 44.1 & $913.5 \pm 92.1$ & 891 \\
$>1200$ & $41.8 \pm 3.3$ & 43.6 & $46.5 \pm 3.3$ & 48.3 & $1594.6 \pm 580.0$ & 1225 \\
\hline
\end{tabular}

Me - median. Other abbreviations as in Table 1.

Table 4. Respondents who noticed or were annoyed by the wind turbine noise ${ }^{1}$

\begin{tabular}{|c|c|c|c|c|}
\hline \multirow{3}{*}{ Group of respondents } & \multicolumn{4}{|c|}{$\begin{array}{l}\text { Respondents } \\
{[\%(95 \% \text { CI })]}\end{array}$} \\
\hline & \multicolumn{2}{|c|}{ do notice noise from wind turbines } & \multicolumn{2}{|c|}{ annoyed by noise from wind turbines } \\
\hline & outdoors & indoors & outdoors & indoors \\
\hline Respondents (total) & $60.3(52.6-67.9)$ & $39.7(32.1-47.4)$ & $33.3(26.3-41.0)$ & $20.5(14.1-26.9)$ \\
\hline \multicolumn{5}{|l|}{ Noise category $(\mathrm{dB})$} \\
\hline $30-35$ & $50.0(16.7-83.3)$ & $16.7(1.1-58.2)$ & $0.0(0.0-44.3)$ & $0.0(0.0-44.3)$ \\
\hline $35-40$ & $54.2(40.7-66.1)$ & $40.7(28.8-52.5)$ & $27.1(16.9-39.0)$ & $18.6(8.5-28.8)$ \\
\hline $40-45$ & $61.0(50.6-71.4)$ & $40.3(29.9-51.9)$ & $36.4(26.0-46.8)$ & $23.4(14.3-32.5)$ \\
\hline $45-50$ & $90.9(72.7-100.0)$ & $45.5(18.2-72.7)$ & $63.6(36.4-90.9)$ & $18.2(4.0-48.9)$ \\
\hline \multicolumn{5}{|l|}{ Distance category (m) } \\
\hline$<400$ & $100.0(59.6-100.0)$ & $85.7(57.1-100.0)$ & $71.4(42.9-100.0)$ & $57.1(14.3-85.7)$ \\
\hline $400-800$ & $65.6(56.3-75.0)^{*}$ & $46.9(36.5-57.3)^{*}$ & $35.4(26.0-44.8)$ & $21.9(13.5-30.2)$ \\
\hline $800-1200$ & $46.5(32.6-60.5)^{*}$ & $23.3(11.6-37.2)^{*}$ & $23.3(11.6-37.2)$ & $14.0(4.7-25.6)$ \\
\hline$>1200$ & $28.6(7.6-64.8)$ & $0.0(0.0-40.4)$ & $28.6(7.6-64.8)$ & $0.0(0.0-40.4)$ \\
\hline
\end{tabular}

${ }^{1}$ Only the most numerous noise (35-40 dB and 40-45 dB) and distance categories (400-800 $\mathrm{m}$ and 400-800 m) were compared.

* Significant differences $(\mathrm{p}<0.05)$.

CI - confidence interval. 

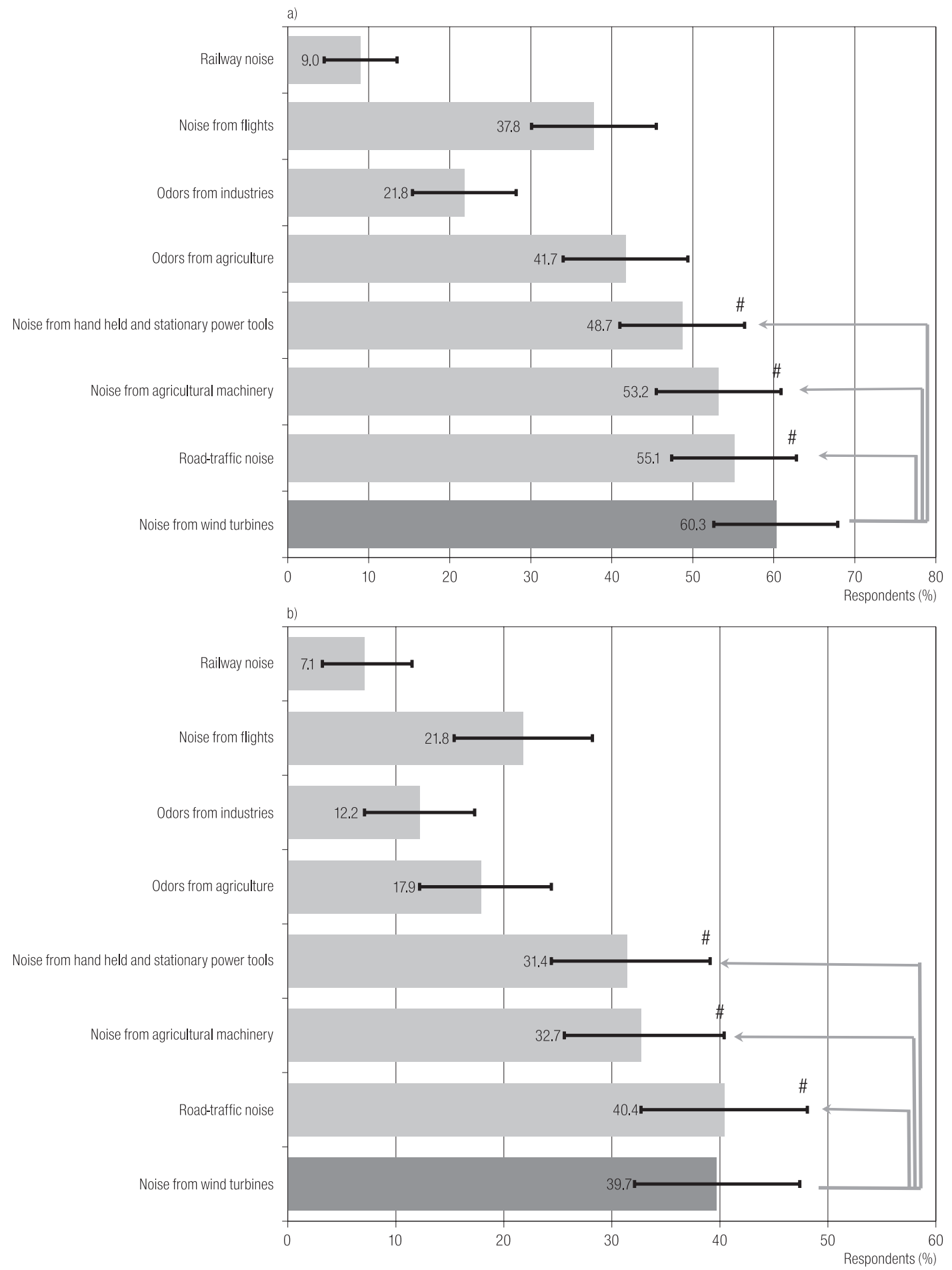

Data are given as proportions with $95 \%$ confidence intervals.

\# No significant differences. To avoid the risk of mass significance, $\mathrm{p}<0.00625$ was required for statistical significance.

Fig. 2. Respondents who noticed the wind turbine noise and other environmental nuisances (a) outdoors and (b) indoors 

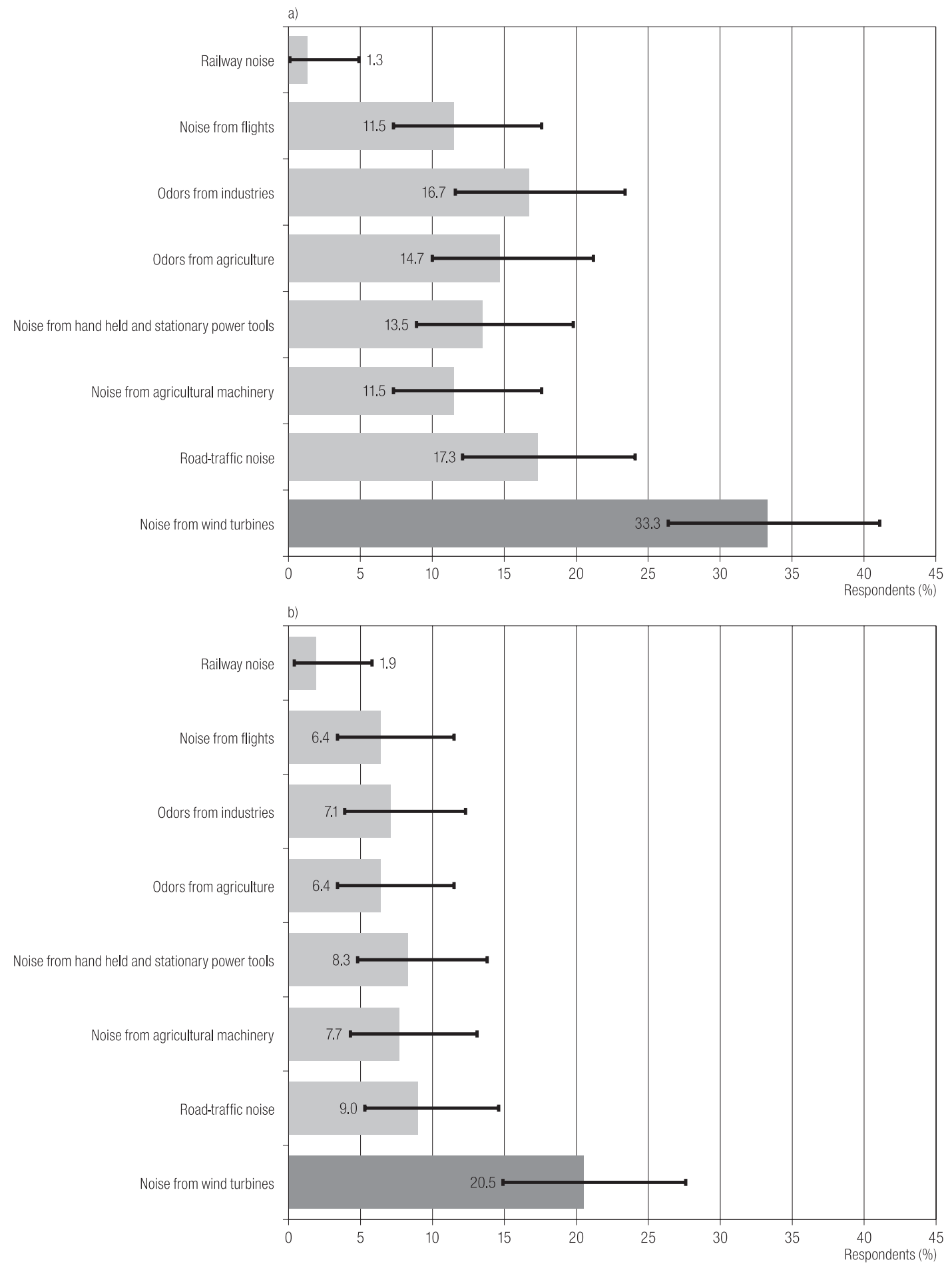

Data are given as proportions with $95 \%$ confidence intervals.

There were significant differences between proportions of the respondents being annoyed by the wind turbine noise and other environmental nuisances. To avoid the risk of mass significance, $p<0.00625$ was required for statistical significance.

Fig. 3. Respondents who were annoyed (a) outdoors and (b) indoors by the wind turbine noise and other environmental nuisances 


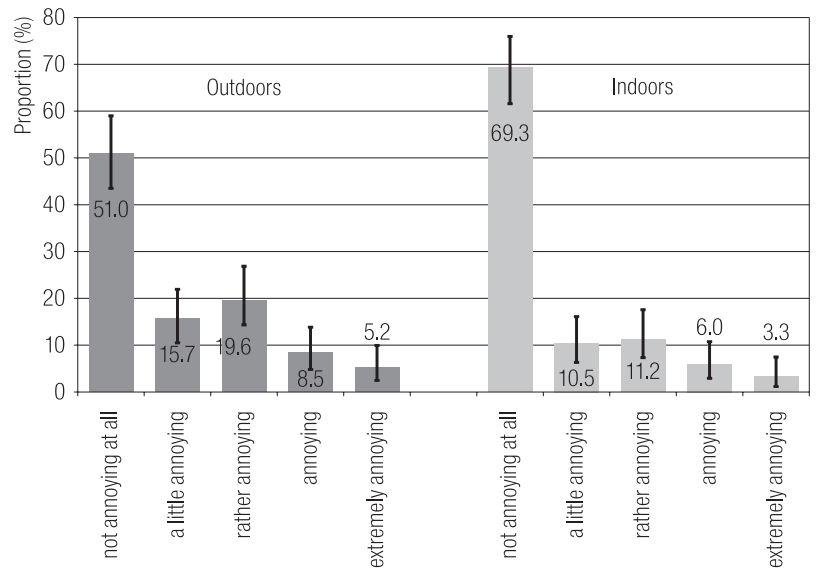

Data are given as proportions with $95 \%$ confidence intervals.

Fig. 4. Distributions of perceived annoyance from wind turbines (outdoors and indoors) in total

those annoyed by the wind turbine noise outdoors also increased along with higher sound pressure levels $(27.1 \%$ at SPL of $35-40 \mathrm{~dB}$ and $36.4 \%$ at $40-45 \mathrm{~dB}$ ). A similar tendency was observed in the case of annoyance perception indoors. However, neither when analyzing annoyance outdoors nor indoors significant differences were observed between the noise categories of 35-40 $\mathrm{dB}$ and $40-45 \mathrm{~dB}$ (Table 4).

The wind turbine noise was most frequently reported when relaxing outdoors (37.8\%) and during quiet outdoor activities (33.3\%), get-together outdoors such as barbecue $(32.1 \%)$ and taking walks (30.8\%) (Table 5). However, the subjects were most often annoyed by the wind turbine noise during relaxing outdoors (26.3\%), taking walks $(23.1 \%)$ as well as quiet outdoor activities $(21.2 \%)$ and get-together outdoors (19.9\%). The proportions of subjects annoyed during relaxing outdoors, get-together outdoors and taking walks decreased significantly from $24-31 \%$ at the distance category of 400-800 $\mathrm{m}$ to 5-7\% in the distance category of 800-1200 m (Table 5).

Generally, over a half of the respondents $(57.1 \%)$ indicated rotor blades as the main source of the wind turbine noise, while noise from the wind turbine machinery was reported only by $16 \%$ of them (Table 6). Similarly, in all noise and distance categories, higher proportions of the respondents noticed noise from the rotor blades than from the machinery. The proportions of subjects who noticed noise from rotor blades were similar to the proportions of subjects who noticed the wind turbine noise in general (Figure 5).

The rotor blades as a main source of noise were less frequently reported at the distance of $800-1200 \mathrm{~m}$ than $400-800$ m (39.5 vs. $66.7 \%$, p < 0.05). Moreover, proportions of the respondents who frequently ("almost every day" or "at least once a week / several times a week") perceived noise from the rotor blades increased significantly from $8.5 \%$ in the noise category of $35-40 \mathrm{~dB}$ to $26 \%$ in noise category of 40-45 dB.

The most frequent verbal descriptors of noise characteristics were "rustling" $(28.2 \%, 95 \%$ CI: 21.2-35.3), "swishing" (26.9\%, 95\% CI: 19.9-34.0) and quiet (23.1\%, 95\% CI: 16.7-30.1). Weather conditions had some impact on the noise perception. Of the total number of respondents, 39.7\% (95\% CI: 32.1-47.4) reported that they could hear the noise more clearly than usual when the wind was blowing from turbine towards their dwelling, while only $5.8 \%$ (95\% CI: 2.6-9.6) - when the

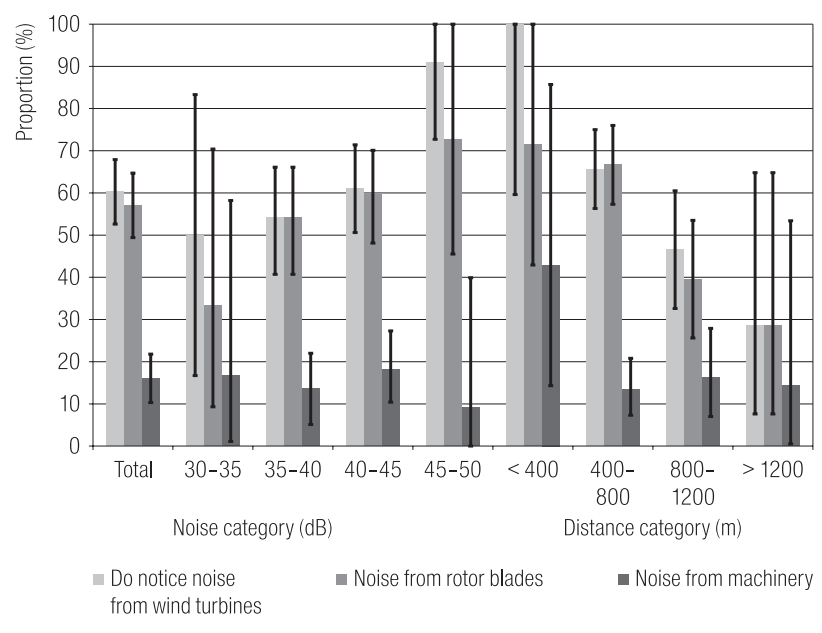

Data are given as proportions with $95 \%$ confidence intervals.

Fig. 5. Respondents who perceived outdoors the noise from wind turbines in general, from rotor blades and from machinery 
Table 5. Respondents who noticed or were annoyed by the wind turbine noise during various activities

\begin{tabular}{lccccc}
\hline \multirow{2}{*}{ Answer } & \multicolumn{5}{c}{$\begin{array}{c}\text { Respondents } \\
{[\%(95 \% \mathrm{CI})]}\end{array}$} \\
\cline { 2 - 6 } & \multirow{2}{*}{ total } & \multicolumn{2}{c}{ noise category } & \multicolumn{2}{c}{ distance category } \\
\cline { 2 - 6 } & & $35-40 \mathrm{~dB}$ & $40-45 \mathrm{~dB}$ & $400-800 \mathrm{~m}$ & $800-1200 \mathrm{~m}$ \\
\hline $\begin{array}{l}\text { Do notice noise from the wind } \\
\text { turbines during }\end{array}$ & & & & \\
relaxing outdoors & $37.8(30.1-45.5)$ & $30.5(18.6-42.4)$ & $39.0(28.6-49.4)$ & $39.6(30.2-49.0)$ & $27.9(14.0-41.9)$ \\
get-together outdoors & $32.1(25.0-39.7)$ & $23.7(13.6-35.6)$ & $36.4(26.0-46.8)$ & $35.4(26.0-44.8)^{*}$ & $14.0(4.7-25.6)^{*}$ \\
taking walks & $30.8(23.7-37.8)$ & $25.4(15.3-37.3)$ & $33.8(23.4-44.2)$ & $31.3(21.9-40.6)$ & $20.9(9.3-32.6)$ \\
quiet outdoor activities & $33.3(26.3-41.0)$ & $30.5(18.6-42.4)$ & $35.1(24.7-45.5)$ & $31.3(21.9-40.6)$ & $27.9(14.0-41.9)$ \\
noisy outdoor activities & $19.9(14.1-26.3)$ & $16.9(8.5-27.1)$ & $19.5(11.7-28.6)$ & $19.8(12.5-28.1)$ & $11.6(2.3-20.9)$ \\
relaxing indoors & $23.7(17.3-30.8)$ & $27.1(16.9-39.0)$ & $18.2(10.4-27.3)$ & $20.8(13.5-29.2)$ & $20.9(9.3-32.6)$ \\
indoor activities & $16.0(10.3-21.8)$ & $16.9(8.5-27.1)$ & $14.3(6.5-22.1)$ & $14.6(8.3-21.9)$ & $11.6(2.3-20.9)$ \\
Annoyed by noise from the wind & & & & & \\
turbines during & & & & & \\
relaxing outdoors & & & & & \\
get-together outdoors & $26.3(19.2-33.3)$ & $22.0(11.9-32.2)$ & $27.3(18.2-37.7)$ & $31.3(21.9-40.6)^{*}$ & $7.0(1.7-19.3)^{*}$ \\
taking walks & $19.9(14.1-26.3)$ & $18.6(8.5-28.8)$ & $20.8(11.7-29.9)$ & $24.0(15.6-32.3)^{*}$ & $4.7(0.4-16.3)^{*}$ \\
quiet outdoor activities & $23.1(16.7-30.1)$ & $20.3(10.2-30.5)$ & $26.0(16.9-36.4)$ & $28.1(19.8-37.5)^{*}$ & $4.7(0.4-16.3)^{*}$ \\
noisy outdoor activities & $21.2(14.7-27.6)$ & $23.7(13.6-35.6)$ & $20.8(11.7-29.9)$ & $21.9(13.5-30.2)$ & $11.6(2.3-20.9)$ \\
relaxing indoors & $9.6(5.1-14.7)$ & $8.5(1.7-16.9)$ & $9.1(3.9-15.6)$ & $11.5(5.2-17.7)^{*}$ & $0.0(0.0-9.8)^{*}$ \\
indoor activities & $14.7(9.6-20.5)$ & $18.6(8.5-28.8)$ & $13.0(6.5-20.8)$ & $15.6(8.3-22.9)$ & $9.3(2.3-18.6)$ \\
other activities & $7.7(3.8-12.2)$ & $8.5(1.7-16.9)$ & $7.8(2.6-14.3)$ & $9.4(4.2-15.6)^{*}$ & $0.0(0.0-9.8)^{*}$ \\
\hline & $5.1(1.9-9.0)$ & $6.8(1.7-13.6)$ & $5.2(1.3-10.4)$ & $7.3(2.1-12.5)$ & $0.0(0.0-9.8)$ \\
\hline
\end{tabular}

* Significant differences between distance categories $(\mathrm{p}<0.05)$.

CI - confidence interval.

Table 6. Main sources of the wind turbine noise and its perception outdoors

\begin{tabular}{|c|c|c|c|c|c|}
\hline \multirow{3}{*}{ Answer } & \multicolumn{5}{|c|}{$\begin{array}{l}\text { Respondents } \\
{[\%(95 \% \mathrm{CI})]}\end{array}$} \\
\hline & \multirow{2}{*}{ total } & \multicolumn{2}{|c|}{ noise category } & \multicolumn{2}{|c|}{ distance category } \\
\hline & & $35-40 \mathrm{~dB}$ & $40-45 \mathrm{~dB}$ & $400-800 \mathrm{~m}$ & $800-1200 \mathrm{~m}$ \\
\hline \multicolumn{6}{|c|}{$\begin{array}{l}\text { Main source of the wind turbine } \\
\text { noise }\end{array}$} \\
\hline rotor blades & $57.1(49.4-64.7)$ & $54.2(40.7-66.1)$ & $59.7(48.1-70.1)$ & $66.7(57.3-76.0)^{*}$ & $39.5(25.6-53.5)^{3}$ \\
\hline machinery & $16.0(10.3-21.8)$ & $13.6(5.1-22.0)$ & $18.2(10.4-27.3)$ & $13.5(7.3-20.8)$ & $16.3(7.0-27.9)$ \\
\hline other & $1.3(0.1-4.9)$ & $0.0(0.0-7.3)$ & $2.6(0.2-9.5)$ & $1.0(0.0-6.2)$ & $0.0(0.0-9.8)$ \\
\hline do not know & $8.3(4.8-13.8)$ & $3.4(0.3-12.2)$ & $9.1(3.9-15.6)$ & $9.4(4.2-15.6)$ & $7.0(1.7-19.3)$ \\
\hline
\end{tabular}


Table 6. Main sources of the wind turbine noise and its perception outdoors - cont.

\begin{tabular}{|c|c|c|c|c|c|}
\hline \multirow{3}{*}{ Answer } & \multicolumn{5}{|c|}{$\begin{array}{l}\text { Respondents } \\
{[\%(95 \% \mathrm{CI})]}\end{array}$} \\
\hline & \multirow{2}{*}{ total } & \multicolumn{2}{|c|}{ noise category } & \multicolumn{2}{|c|}{ distance category } \\
\hline & & $35-40 \mathrm{~dB}$ & $40-45 \mathrm{~dB}$ & $400-800 \mathrm{~m}$ & $800-1200 \mathrm{~m}$ \\
\hline \multicolumn{6}{|c|}{$\begin{array}{l}\text { Do notice frequent noise } \\
\text { from }\end{array}$} \\
\hline rotor blades & $18.6(12.8-25.0)$ & $8.5(1.7-16.9)^{*}$ & $26.0(16.9-36.4)^{*}$ & $21.9(13.5-30.2)$ & $9.3(2.3-18.6)$ \\
\hline machinery & $10.3(5.8-15.4)$ & $5.1(1.2-14.5)$ & $13.0(6.5-20.8)$ & $12.5(6.3-19.8)$ & $2.3(0.0-13.2)$ \\
\hline other sources & $25.6(19.2-32.7)$ & $23.7(13.6-35.6)$ & $27.3(18.2-37.7)$ & $29.2(19.8-38.5)$ & $14.0(4.7-25.6)$ \\
\hline
\end{tabular}

Do notice "frequently" noise from the indicated source means "almost every day" or "at least once a week".

* Significant differences between distance categories $(\mathrm{p}<0.05)$.

CI - confidence interval.

wind was from the opposite direction. The noise was more clearly heard when a rather strong wind was blowing (47.4\%, 95\% CI: 39.7-55.1) and during warm summer nights (30.8\%, 95\% CI: 23.7-37.8). However, $10.3 \%$ (95\% CI: 5.8-15.4) of the subjects noticed the noise more clearly in low wind. Similar relations were observed in all the analyzed noise and distance categories.

Besides the noise, also the shadow flickers and reflections from rotor blades were perceived as annoying - by $23.7 \%$ and $12.8 \%$ of the subjects, respectively (Table 7). Almost a half $(49.4 \%)$ of the respondents noticed shadow flickers accompanying operation of wind turbines, while reflections from rotor blades were noticed by $23.1 \%$. In particular, the proportions of subjects who noticed and perceived the annoyance from shadow flickers were significantly higher in the noise category of $40-45 \mathrm{~dB}$ than in the noise category of 35-40 dB (Table 7). Similar relationships (i.e., significant differences) were observed when analyzing perception and annoyance due to shadow flickering in the distance categories of $400-800 \mathrm{~m}$ and $800-1200 \mathrm{~m}$.

\section{Subjective and objective factors influencing annoyance}

Generally, there were significant correlations between the noise and the distance categories as well as the subjective variables and noise annoyance rating on a 5 -score verbal rating scale (Table 8). In particular, there was a weak, but statistically significant, correlation between the noise category and annoyance related to the noise from the main source (Spearman's rank correlation coefficient $\left.r_{s}=0.23, p<0.05\right)$. On the other hand, annoyance related to the wind turbines noise indoors and during get-together outdoors were weakly correlated with the distance category.

The highest values of the Spearman's rank correlation coefficient were noted for the general attitude to wind turbines and attitude to their visual impact in particular $\left(r_{s} \geq-0.68\right.$, $\mathrm{p}<0.00625)$. Relatively strong correlations were also observed between sensitivity to landscape littering and annoyance related to the wind turbine noise outdoors in general as well as to the main source of the wind turbine noise $\left(r_{s} \leq 0.54, p<0.00625\right)$, while weaker correlations were found for sensitivity to noise and self-assessment of physical health. On the other hand, the mental health status, expressed in the GHQ-12 score, showed a weak but statistically significant correlation with annoyance due to the wind turbine noise when relaxing outdoors, get-together parties and noisy outdoor activities (Table 8).

Thus, the subjects that were categorized as negative to wind turbine (in general and to the visual impact of wind turbines in particular) noticed and perceived noise from 
Table 7. Respondents who noticed or were annoyed by nuisances, other than noise, accompanying operation of the wind turbines

\begin{tabular}{|c|c|c|c|c|c|}
\hline \multirow{3}{*}{ Answer } & \multicolumn{5}{|c|}{$\begin{array}{l}\text { Respondents } \\
{[\%(95 \% \mathrm{CI})]}\end{array}$} \\
\hline & \multirow{2}{*}{ total } & \multicolumn{2}{|c|}{ noise category } & \multicolumn{2}{|c|}{ distance category } \\
\hline & & $35-40 \mathrm{~dB}$ & $40-45 \mathrm{~dB}$ & $400-800 \mathrm{~m}$ & $800-1200 \mathrm{~m}$ \\
\hline \multicolumn{6}{|l|}{ Do notice } \\
\hline shadow flicker & $49.4(41.7-57.1)$ & $28.8(16.9-40.7)^{*}$ & $59.7(48.1-70.1)^{*}$ & $59.4(50.0-68.8)^{*}$ & $25.6(14.0-39.5)^{*}$ \\
\hline reflection from rotor blades & $23.1(16.7-30.1)$ & $16.9(8.5-27.1)$ & $23.4(14.3-32.5)$ & $24.0(15.6-32.3)$ & $14.0(4.7-25.6)$ \\
\hline \multicolumn{6}{|l|}{ Annoyed by } \\
\hline shadow flicker & $23.7(17.3-30.8)$ & $6.8(1.7-13.6)^{*}$ & $33.8(23.4-44.2)^{*}$ & $28.1(19.8-37.5)^{*}$ & $11.6(2.3-20.9)^{*}$ \\
\hline reflection from rotor blades & $12.8(7.7-18.6)$ & $5.1(1.2-14.5)^{*}$ & $18.2(10.4-27.3)^{*}$ & $14.6(8.3-21.9)$ & $4.7(0.4-16.3)$ \\
\hline
\end{tabular}

* Significant differences between noise and distance categories $(\mathrm{p}<0.05)$.

CI - confidence interval.

Table 8. Relationships between annoyance related to the wind turbines, noise category, distance category and the subjective factors ${ }^{1}$

\begin{tabular}{|c|c|c|c|c|c|c|c|c|}
\hline \multirow[b]{2}{*}{ Annoyance } & \multicolumn{8}{|c|}{ Spearman's rank correlation coefficient } \\
\hline & $\begin{array}{c}\text { noise } \\
\text { category }\end{array}$ & $\begin{array}{l}\text { distance } \\
\text { category }\end{array}$ & $\begin{array}{l}\text { sensitivity } \\
\text { to noise }\end{array}$ & $\begin{array}{c}\text { sensitivity } \\
\text { to } \\
\text { landscape } \\
\text { littering }\end{array}$ & $\begin{array}{l}\text { attitude } \\
\text { to wind } \\
\text { turbines in } \\
\text { general }\end{array}$ & $\begin{array}{c}\text { attitude } \\
\text { to visual } \\
\text { impact } \\
\text { of wind } \\
\text { turbines }\end{array}$ & $\begin{array}{c}\text { self- } \\
\text { assessment } \\
\text { of physical } \\
\text { health }\end{array}$ & $\begin{array}{l}\text { score } \\
\text { in the } \\
\text { GHQ-12 }\end{array}$ \\
\hline \multicolumn{9}{|l|}{ Related to } \\
\hline wind turbine noise outdoors & 0.17 & -0.20 & $0.31^{*}$ & $0.53^{*}$ & $-0.68^{*}$ & $-0.63^{*}$ & $-0.32 *$ & 0.23 \\
\hline wind turbine noise indoors & 0.10 & $-0.27^{*}$ & 0.12 & $0.32 *$ & $-0.54^{*}$ & $-0.51^{*}$ & $-0.27^{*}$ & 0.17 \\
\hline main source of wind turbine noise & $0.23^{*}$ & -0.22 & $0.35^{*}$ & $0.54^{*}$ & $-0.46^{*}$ & $-0.42^{*}$ & $-0.23^{*}$ & 0.16 \\
\hline \multicolumn{9}{|l|}{ From wind turbine noise during } \\
\hline relaxing outdoors & 0.19 & -0.20 & $0.25^{*}$ & $0.50^{*}$ & $-0.65^{*}$ & $-0.62 *$ & $-0.36^{*}$ & $0.25^{*}$ \\
\hline get-together outdoors & 0.13 & $-0.24^{*}$ & 0.22 & $0.39^{*}$ & $-0.68^{*}$ & $-0.61^{*}$ & $-0.34^{*}$ & $0.25^{*}$ \\
\hline taking walks & 0.09 & -0.22 & 0.22 & $0.41^{*}$ & $-0.68^{*}$ & $-0.64^{*}$ & $-0.29 *$ & 0.22 \\
\hline quiet outdoor activities & 0.07 & -0.16 & 0.20 & $0.39^{*}$ & $-0.64^{*}$ & $-0.58^{*}$ & $-0.28 *$ & 0.24 \\
\hline noisy outdoor activities & -0.02 & 0.01 & 0.15 & 0.19 & $-0.33^{*}$ & $-0.28^{*}$ & $-0.29 *$ & $0.25^{*}$ \\
\hline relaxing indoors & -0.12 & -0.08 & 0.22 & 0.21 & $-0.48^{*}$ & $-0.46^{*}$ & -0.22 & 0.09 \\
\hline indoor activities & -0.06 & -0.18 & 0.16 & 0.21 & $-0.49^{*}$ & $-0.44^{*}$ & $-0.32^{*}$ & 0.10 \\
\hline
\end{tabular}

${ }^{1}$ Except for the score in the GHQ-12, analyzed variables are given in 5-point or 6-point scale. To avoid the risk of mass significance, $\mathrm{p}<0.00625$ was required for statistical significance.

* Statistically significant correlations ( $\mathrm{p}<0.00625)$.

GHQ-12 - 12-item Goldberg's General Health Questionnaire.

the wind turbines as annoying more frequently than other respondents (Table 9). Likewise, the respondents who assessed their health as poor, were more often annoyed outdoors by the wind turbine noise than others. On the other hand, there were no significant differences in noise annoyance rating between the high- and low-scored subjects in the GHQ-12 ( $p>0.00138$ ). The latter factor affected only the proportion of subjects who noticed the wind turbine 
noise during noisy outdoor activities; the high-scored subjects perceived noise more often than the low-scored ones (33.9\% (95\% CI: $22.0-45.8)$ vs. 8.2\% (95\% CI: 2.7-15.1), respectively, $\mathrm{p}<0.00138)$. Generally, there were no significant differences between females and males or the younger and older subjects in the perception of annoyance due to the wind turbine noise.

In order to analyze the impact of both, objective and subjective factors on noise annoyance, the binary multiple logistic regression was applied with the logistic model expressed as follows:

$$
p=\frac{e^{\left(b_{0}+b_{1} x_{1}+b_{2} x_{2}+\ldots+b_{n} x_{n}\right)}}{1+e^{\left(b_{0}+b_{1} x_{1}+b_{2} x_{2}+\ldots+b_{n} x_{n}\right)}}
$$

where:

p - is the probability of being annoyed ("rather annoyed", "annoyed" or "extremely annoyed") by the noise from wind turbines outdoors;

$\mathrm{x}_{1}-\mathrm{x}_{\mathrm{n}}$ - are the explanatory variables included in the model, e.g., noise category, attitude towards the wind turbines in general, etc.;

$\mathrm{b}_{\mathrm{o}}, \mathrm{b}_{1}, \ldots \mathrm{b}_{\mathrm{n}}$ - are the regression coefficients, i.e., the logarithmic values of the odds ratio for the unit change in the respective variables.

Explanatory variables were: noise and distance categories, attitude to wind turbines in general and to their visual impact, sensitivity to noise and landscape littering, selfassessment of physical health and mental health status expressed in the GHQ-12 score. Fourteen various models were created, including those containing each explanatory variable separately (Table 10).

In the first model only the noise category was used as an independent variable. The $\operatorname{Exp}(b)=2.1$, i.e., the odds ratio of being annoyed by the noise from the wind turbines would increase 2.1 times from one sound category to the next. The pseudo- $\mathrm{R}^{2}$ was 0.070 , indicating that noise category explained only $7 \%$ of the variance in annoyance. Similar result (pseudo- $\mathrm{R}^{2}=0.04$ ) was obtained for the distance category as an explanatory variable (see model no. 2). On the other hand, general attitude to wind turbines (model no. 4) explained $43.1 \%$ of variance in annoyance. Thus, after adding to noise the general attitude to wind turbines as an explanatory variable (model no. 12), the pseudo- $\mathrm{R}^{2}$ increased from 0.070 to 0.527 . Including the next subjective factor i.e., attitude to landscape littering (model no. 13) also improved the model (the pseudo- $\mathrm{R}^{2}$ increased to 0.628 ).

The highest value of the explained variance $(63.1 \%)$ was obtained for the model containing noise category, general attitude to wind turbines, sensitivity to landscape littering and the GHQ-12 score as explanatory variables (model no. 14). It is worth to underline that almost all regression coefficients in the above models, excluding regression coefficient for the distance category in model no. 9, reached statistical significance (Table 10).

\section{Self-assessment of well-being}

Majority of the respondents (76.9\%) assessed their physical health as "good" or "very good" and rather rarely ("never" / "almost never" or "a few times per year or month") reported headache (75\%), dizziness (84.6\%), heartache $(82.1 \%)$, undue tiredness $(71.2 \%)$, insomnia $(80.8 \%)$, pain and stiffness in back, neck or shoulders (77.6\%), dyspnea (85.9\%) as well as feeling nervous, tension or stress $(66.7 \%)$. Excluding insomnia, similar proportions were noted in all the noise and distance categories. The proportion of subjects often (i.e., "every day / almost every day" or "a few times per week") suffering from insomnia was higher in the noise category of 40-45 dB than 35-40 dB (26\% (95\% CI: 16.9-36.4) vs. $10.2 \%$ (95\% CI: $3.4-18.6$ ), respectively, $\mathrm{p}<0.05$ ). It is not surprising that the subjects with negative selfassessment of physical health reported those complaints more often than others (Table 11).

There were no significant differences between females and males as well as younger and older sub- 
Table 9. Respondents who noticed or were annoyed due to the noise from wind turbine in the subgroups of subjects of different gender, age, attitude towards wind turbines and environmental nuisances as well as physical health status ${ }^{1}$

\begin{tabular}{|c|c|c|c|c|}
\hline \multirow{3}{*}{ Subgroup of subjects } & \multicolumn{4}{|c|}{$\begin{array}{l}\text { Respondents } \\
{[\%(95 \% \mathrm{CI})]}\end{array}$} \\
\hline & \multicolumn{2}{|c|}{ do notice the wind turbine noise } & \multicolumn{2}{|c|}{ annoyed by the wind turbine noise } \\
\hline & outdoors & indoors & outdoors & indoors \\
\hline \multicolumn{5}{|l|}{ Gender } \\
\hline females & $57.1(47.3-67.0)$ & $41.8(31.9-51.6)$ & $36.3(26.4-46.2)$ & $22.0(14.3-30.8)$ \\
\hline males & $67.7(56.5-79.0)$ & $38.7(27.4-51.6)$ & $30.6(19.4-41.9)$ & $19.4(9.7-29.0)$ \\
\hline \multicolumn{5}{|l|}{ Age } \\
\hline older subjects & $56.8(45.9-67.6)$ & $39.2(28.4-50.0)$ & $29.7(20.3-40.5)$ & $18.9(10.8-28.4)$ \\
\hline younger subjects & $60.3(49.3-71.2)$ & $37.0(26.0-47.9)$ & $34.2(23.3-45.2)$ & $20.5(12.3-30.1)$ \\
\hline \multicolumn{5}{|c|}{ Mental health status according to GHQ-12 } \\
\hline cases & $64.3(35.7-85.7)$ & $57.1(28.6-78.6)$ & $50.0(21.4-78.6)$ & $42.9(21.4-71.4)$ \\
\hline others & $63.6(55.1-72.0)$ & $36.4(28.0-44.9)$ & $32.2(23.7-40.7)$ & $16.9(10.2-23.7)$ \\
\hline \multicolumn{5}{|l|}{ Score in GHQ-12 } \\
\hline high-scored & $66.1(54.2-78.0)$ & $40.7(28.8-52.5)$ & $45.8(33.9-59.3)$ & $25.4(15.3-37.3)$ \\
\hline low-scored & $61.6(50.7-72.6)$ & $37.0(26.0-47.9)$ & $24.7(15.1-34.2)$ & $15.1(6.8-23.3)$ \\
\hline \multicolumn{5}{|l|}{ Self-assessment of physical health } \\
\hline negative & $78.8(63.6-90.9)$ & $60.6(42.4-75.8)$ & $57.6(39.4-72.7)^{*}$ & $33.3(18.2-48.5)$ \\
\hline positive & $56.7(47.5-65.8)$ & $34.2(25.8-42.5)$ & $27.5(20.0-35.8)^{*}$ & $17.5(10.8-24.2)$ \\
\hline \multicolumn{5}{|l|}{ Attitude to landscape littering } \\
\hline sensitive & $80.5(72.0-89.0)^{*}$ & $52.4(41.5-63.4)^{*}$ & $50.0(39.0-61.0)^{*}$ & $28.0(18.3-37.8)$ \\
\hline not sensitive & $38.2(26.5-50.0)^{*}$ & $25.0(14.7-35.3)^{*}$ & $13.2(5.9-22.1)^{*}$ & $11.8(4.4-20.6)$ \\
\hline \multicolumn{5}{|l|}{ Attitude to noise } \\
\hline sensitive & $73.3(64.4-82.2)^{*}$ & $43.3(33.3-53.3)$ & $42.2(32.2-52.2)$ & $17.8(10.0-25.6)$ \\
\hline not sensitive & $42.1(29.8-54.4)^{*}$ & $33.3(21.1-45.6)$ & $17.5(8.8-28.1)$ & $8.8(1.8-17.5)$ \\
\hline \multicolumn{5}{|l|}{ Attitude to wind turbines in general } \\
\hline negative & $93.5(83.9-100.0)^{*}$ & $80.6(64.5-93.5)^{*}$ & $90.3(77.4-100.0)^{*}$ & $61.3(45.2-77.4)^{*}$ \\
\hline positive & $53.3(44.2-62.5)^{*}$ & $29.2(20.8-37.5)^{*}$ & $19.2(12.5-26.7)^{*}$ & $10.8(5.8-16.7)^{*}$ \\
\hline \multicolumn{5}{|c|}{ Attitude to visual impact of wind turbines } \\
\hline negative & $90.6(78.1-100.0)^{*}$ & $71.9(56.3-87.5)^{*}$ & $81.3(65.6-93.8)^{*}$ & $50.0(31.3-68.8)^{*}$ \\
\hline positive & $53.8(44.5-63.0)^{*}$ & $31.1(22.7-39.5)^{*}$ & $21.0(14.3-28.6)^{*}$ & $12.6(6.7-18.5)^{*}$ \\
\hline
\end{tabular}

${ }^{1}$ To avoid the risk of mass significance, $\mathrm{p}<0.00138$ was set for statistical significance.

* Significant differences between subgroups ( $\mathrm{p}<0.00138)$.

GHQ-12 - 12-item Goldberg's General Health Questionnaire; CI - confidence interval.

jects $(p>0.00138)$. On the other hand, the subjects' gen- dents with the negative attitude to wind turbines reported eral attitude to wind turbine influenced the reported fre- that they had felt nervous or experienced tension or stress quency of feeling nervous or tense / stressed. The respon- " "everyday" / "almost every day" or "a few times per week" 
Table 10. Multiple logistic regression analyses with $95 \%$ confidence intervals $(\mathrm{CI})^{1}$

\begin{tabular}{|c|c|c|c|c|c|}
\hline $\begin{array}{l}\text { Model } \\
\text { no. }\end{array}$ & Variable & $\begin{array}{l}\text { Regression coefficient } \\
(95 \% \mathrm{CI})\end{array}$ & $\mathrm{p}$ & $\begin{array}{l}\text { Odds ratio } \\
(95 \% \mathrm{CI})\end{array}$ & Pseudo- $\mathrm{R}^{2}$ \\
\hline 1 & noise category & $0.74(0.20-1.29)$ & 0.007 & $2.10(1.22-3.62)$ & 0.070 \\
\hline 2 & distance category & $-0.60((-1.19)-(-0.02))$ & 0.044 & $0.55(0.30-0.98)$ & 0.040 \\
\hline 3 & attitude to visual impact of wind turbines & $2.79(1.79-3.79)$ & 0.000 & $16.29(6.00-44.26)$ & 0.322 \\
\hline 4 & attitude to wind turbines in general & $3.67(2.39-4.96)$ & 0.000 & $39.36(10.89-142.29)$ & 0.431 \\
\hline 5 & sensitivity to noise & $1.23(0.43-2.04)$ & 0.003 & $3.43(1.53-7.70)$ & 0.093 \\
\hline 6 & sensitivity to landscape littering & $1.88(1.05-2.71)$ & 0.000 & $6.56(2.86-15.05)$ & 0.206 \\
\hline 7 & self-assessment of physical health & $1.27(0.47-2.08)$ & 0.002 & $3.58(1.60-8.00)$ & 0.088 \\
\hline 8 & GHQ-12 score & $0.95(0.20-1.69)$ & 0.013 & $2.58(1.22-5.43)$ & 0.065 \\
\hline \multirow[t]{2}{*}{9} & noise category & $0.63(0.06-1.20)$ & 0.030 & $1.88(1.06-3.31)$ & 0.084 \\
\hline & distance category & $-0.38(-0.98-0.22)$ & 0.215 & $0.68(0.37-1.25)$ & \\
\hline \multirow[t]{2}{*}{10} & noise category & $0.75(0.15-1.35)$ & 0.014 & $2.12(1.16-3.85)$ & 0.131 \\
\hline & GHQ-12 score & $0.79(0.02-1.57)$ & 0.045 & $2.21(1.02-4.80)$ & \\
\hline \multirow[t]{2}{*}{11} & noise category & $0.72(0.15-1.30)$ & 0.014 & $2.06(1.16-3.66)$ & 0.269 \\
\hline & sensitivity to landscape littering & $1.95(1.07-2.83)$ & 0.000 & $7.04(2.92-16.95)$ & \\
\hline \multirow[t]{2}{*}{12} & noise category & $1.07(0.35-1.79)$ & 0.004 & $2.91(1.42-5.98)$ & 0.527 \\
\hline & attitude to wind turbines in general & $4.30(2.72-5.87)$ & 0.000 & $73.50(15.25-354.33)$ & \\
\hline \multirow[t]{3}{*}{13} & noise category & $0.87(0.15-1.59)$ & 0.018 & $2.39(1.17-4.91)$ & 0.628 \\
\hline & attitude to wind turbines in general & $4.92(2.74-7.10)$ & 0.000 & $137.24(15.47-1217.86)$ & \\
\hline & sensitivity to landscape littering & $1.91(0.73-3.10)$ & 0.002 & $6.78(2.07-22.27)$ & \\
\hline \multirow[t]{4}{*}{14} & noise category & $0.88(0.08-1.68)$ & 0.032 & $2.41(1.08-5.38)$ & 0.631 \\
\hline & attitude to wind turbines in general & $4.83(2.55-7.12)$ & 0.000 & $125.69(12.77-1236.89)$ & \\
\hline & sensitivity to landscape littering & $1.74(0.49-2.99)$ & 0.007 & $5.71(1.63-19.97)$ & \\
\hline & GHQ-12 score & $1.35(0.21-2.50)$ & 0.020 & $3.88(1.24-12.14)$ & \\
\hline
\end{tabular}

\footnotetext{
${ }^{1}$ Various models were created with objective and subjective factors as explanatory variables of variance in being annoyed by wind turbine noise outdoors.

Pseudo-R2 - the Nagelkerke coefficient of determination, i.e., a measure of explained variance [12]. GHQ-12 - 12-item Goldberg's General Health Questionnaire.
}

(61.3\% (95\% CI: $45.2-77.4)$ vs. $27.5 \%$ (95\% CI: $20-35.8$ ), $\mathrm{p}<0.00138)$ more frequently than those with positive attitude. On the other hand, people who reported annoyance outdoors reported feeling nervous or tense / stressed ( $45.1 \%$ vs. $28.7 \%, \mathrm{p}<0.05$ ), dizziness (28\% vs. $10.2 \%$, $\mathrm{p}<0.05)$ and heartaches (34\% vs. $11.2 \%, \mathrm{p}<0.05)$ more frequently than those not annoyed (Table 11).

Of the total number of respondents, $26.3 \%$ often had (i.e., "everyday" / "almost every day" or "a few times per week") difficulty in falling asleep. Nearly 2/3 (64.1\%) of them often woke up well-rested. Regarding sleep disturbances, $23.1 \%$ of the subjects stated they were disturbed in their sleep by the noise from various sources (including road traffic noise and wind turbine noise) when sleeping with the window open, while only $10.9 \%$ of them were thus disturbed when sleeping with a closed window. Please note that the subjects who reported annoyance outdoors had difficulties with falling asleep more frequently 
Table 11. Respondents who often reported (i.e., "everyday" / "almost every day" or "a few times a week") various complaints in total and in the selected subgroups of respondents ${ }^{1}$

\begin{tabular}{|c|c|c|c|c|c|}
\hline \multirow{3}{*}{ Complaint } & \multicolumn{5}{|c|}{$\begin{array}{l}\text { Respondents } \\
{[\%(95 \% \mathrm{CI})]}\end{array}$} \\
\hline & \multirow{2}{*}{ total } & \multicolumn{2}{|c|}{ assessing their health status as } & \multirow{2}{*}{$\begin{array}{l}\text { not annoyed by } \\
\text { wind turbine noise }\end{array}$} & \multirow{2}{*}{$\begin{array}{c}\text { annoyed by } \\
\text { wind turbine noise }\end{array}$} \\
\hline & & good & poor & & \\
\hline Headache & $25.0(18.6-32.1)$ & $18.3(11.7-25.8)^{*}$ & $51.5(33.3-69.7)^{*}$ & $20.8(12.9-28.7)$ & $35.3(21.6-49.0)$ \\
\hline Dizziness & $15.4(10.3-21.2)$ & $6.7(2.5-11.7)^{*}$ & $48.5(30.3-66.7)^{*}$ & $10.2(5.1-16.3)^{* *}$ & $28.0(16.0-40.0)^{* *}$ \\
\hline Heartache & $17.9(12.2-24.4)$ & $11.7(6.7-17.5)^{*}$ & $42.4(27.3-60.6)^{*}$ & $11.2(5.1-17.3)^{* *}$ & $34.0(22.0-48.0)^{* *}$ \\
\hline Fatigue (undue tiredness) & $28.8(21.8-35.9)$ & $21.7(14.2-29.2)^{*}$ & $57.6(39.4-72.7)^{*}$ & $27.7(18.8-36.6)$ & $33.3(21.6-47.1)$ \\
\hline Insomnia & $19.2(13.5-25.6)$ & $11.7(6.7-17.5)^{*}$ & $48.5(30.3-66.7)^{*}$ & $16.0(9.0-23.0)$ & $26.9(15.4-38.5)$ \\
\hline $\begin{array}{l}\text { Pain and stiffness in back, } \\
\text { neck or shoulders }\end{array}$ & $22.4(16.0-28.8)$ & $16.7(10-23.3)^{*}$ & $45.5(27.3-63.6)^{*}$ & $20.0(12.0-28.0)$ & $28.8(17.3-42.3)$ \\
\hline Pulsation in ears & $6.4(2.6-10.3)$ & $5.8(1.7-10)$ & $9.1(2.37-24.34)$ & $2.9(0.6-8.7)^{* *}$ & $14.0(6.0-24.0)^{* *}$ \\
\hline Dyspnea & $14.1(9.0-19.9)$ & $7.5(3.3-12.5)^{*}$ & $39.4(24.2-57.6)^{*}$ & $13.1(7.1-20.2)$ & $18.0(8.0-30.0)$ \\
\hline $\begin{array}{l}\text { Nervousness, tension } \\
\text { or stress }\end{array}$ & $33.3(26.3-41.0)$ & $25.0(17.5-33.3)^{*}$ & $66.7(51.5-81.8)^{*}$ & $28.7(19.8-37.6)^{* *}$ & $45.1(31.4-58.8)^{* *}$ \\
\hline Tinnitus & $7.7(3.8-12.2)$ & $6.7(2.5-11.7)$ & $12.1(3-24.2)$ & $5.0(1.0-9.9)$ & $14.0(6.0-24.0)$ \\
\hline
\end{tabular}

${ }^{1}$ To avoid the risk of mass significance, $\mathrm{p}<0.00138$ was set for statistical significance when analyzing the impact of subjective factors.

* Significant differences between subgroups of respondents with negative and positive self-assessment of physical health.

** Significant differences $(\mathrm{p}<0.05)$ between subjects annoyed by wind turbine noise and those not annoyed.

$\mathrm{CI}$ - confidence interval.

than others $(42.9 \%$ (95\% CI: $28.6-57.1)$ vs. $19.6 \%$ (95\% CI: 11.8-27.5), $\mathrm{p}<0.05)$.

\section{General opinion on wind turbines}

When asked for general assessment of wind turbines, the respondents most frequently characterized them as "necessary" (37.2\%), "pretty" (18.6\%), "annoying" (17.3\%), "unnatural" (15.4\%) and "effective" (12.8\%). Almost an equal percentage of the respondents claimed that they were $(16.7 \%)$ or were not $(15.4 \%)$ "friendly to the environment". Moreover, nearly every fifth subject stated that wind turbines negatively affected the landscape scenery (23.1\%) as well as people's health and well-being (19.9\%). It is worth to underline that the subjects from the distance category of 400-800 m more often than those from the distance category of 800-1200 m stated that wind turbines had negative impact on humans (24\% (95\% CI: 15.6-32.3) vs. $9.3 \%$ (95\% CI: 2.3-18.6), $\mathrm{p}<0.05)$ and landscape scenery $(28.1 \%$ (95\% CI: $19.8-37.5)$ vs. $4.7 \%$ (95\% CI: $0.4-16.3), \mathrm{p}<0.05)$ as well as described them as unfriendly to the environment $(19.8 \%$ (95\% CI: $12.5-28.1)$ vs. $2.3 \%$ (95\% CI: $0.0-13.2), \mathrm{p}<0.05)$ and ugly $(13.5 \%$ (95\% CI: $7.3-20.8)$ vs. $2.3 \%$ (95\% CI: $0.0-13.2)$, $\mathrm{p}<0.05)$. On the other hand, the subjects exposed to higher SPL (noise category of $40-45 \mathrm{~dB}$ ) described wind turbines as "natural" less frequently than those exposed to lower SPL (35-40 dB) (0\% (95\% CI: 0.0-5.7) vs. $10.2 \%$ (95\% CI: 3.4-18.6), $\mathrm{p}<0.05$ ).

Similar relationships were observed between the subjects with negative and positive attitudes towards wind turbines in general or to their visual impact in particular (Table 12). Generally, the subjects with a negative attitude more often than others described them as annoying, ineffective, harmful to environment, unnecessary, ugly and unnatural 


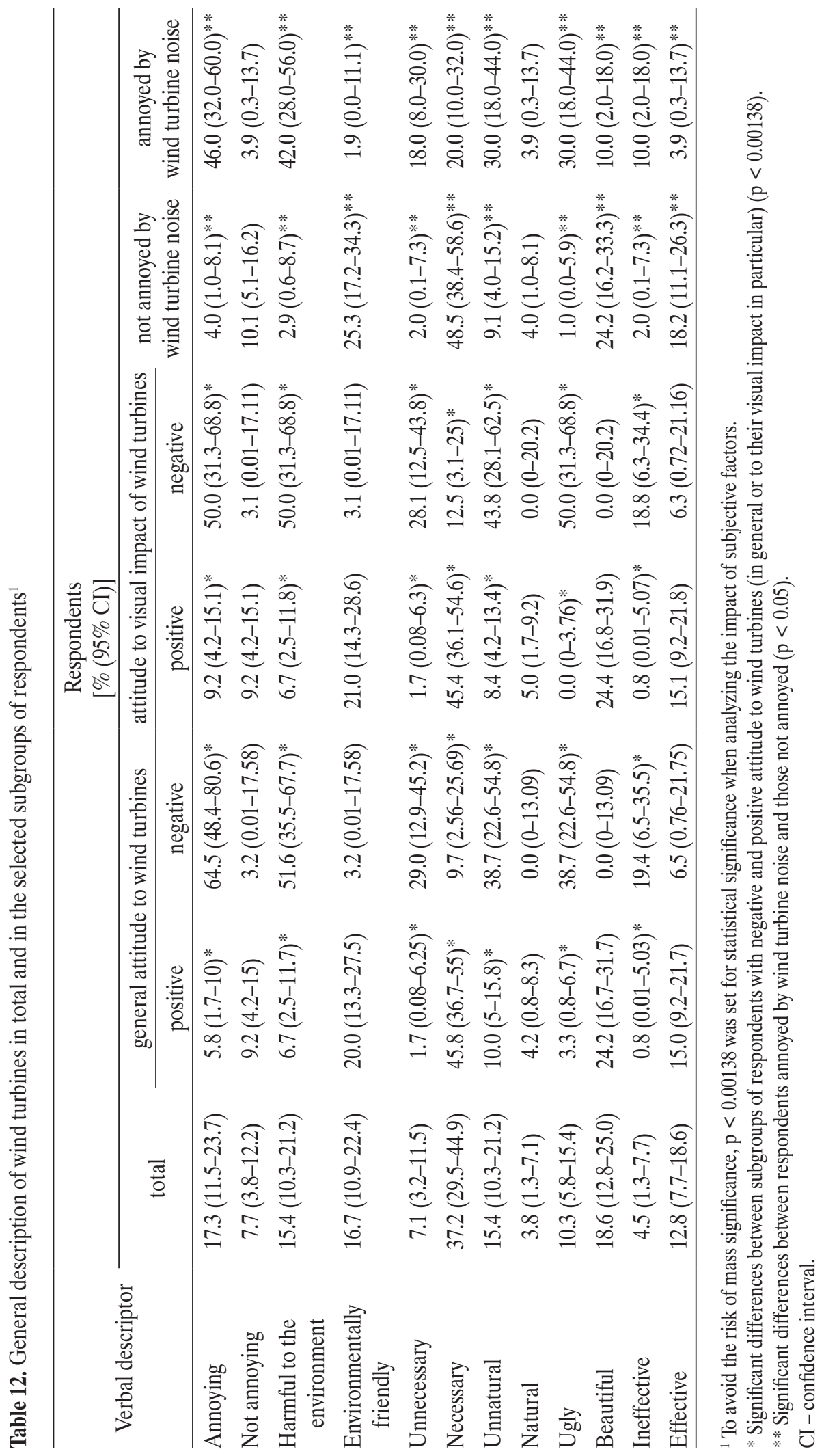


as well as less frequently perceived them as necessary. Moreover, they more often stated that wind turbines negatively affected human health and landscape scenery. Likewise, the respondents who reported annoyance outdoors were more likely than others to assess the wind turbines negatively (Table 12).

\section{DISSCUSION}

Debate concerning potential health effects of wind turbines, specifically in terms of audible and inaudible noise, is still ongoing. So far, most epidemiological evidence concerning the impact of the wind turbine noise on health and well-being comes mainly from 3 cross-sectional studies carried out in Sweden and in the Netherlands between 2000 and 2007 [2-5]. The overall objectives of these investigations were to: i) evaluate the prevalence of perception and annoyance due to the wind turbine noise, ii) analyze individual, environmental and noise-related factors affecting the perceived annoyance, and iii) determine the exposure-response relationships for the wind turbine noise. Questionnaires were mailed to people from 2 areas of Sweden (a flat rural landscape $(\mathrm{N}=351)$ and suburban sites with hilly terrain $(\mathrm{N}=754)$ ) and 1 location in the Netherlands (flat landscape with different road traffic intensity $(\mathrm{N}=725))$ in order to collect data on annoyance and other health effects (such as sleep disturbance, stress) due to the wind turbine noise and potential moderating variables (such as attitude and sensitivity to noise), and self-reported clinical diseases. The questionnaire was constructed in order to mask the main intention and therefore, it also included questions about other several potential environmental stressors (nuisances) [2-4].

Noise exposures in the areas where respondents lived were estimated using the predicted A-weighted sound pressure levels, which were calculated from sound power levels of all wind turbines nearby (logarithmically added). Calculated SPLs ranged from $24 \mathrm{~dB}$ to $54 \mathrm{~dB}$ in the Dutch study and approximately from $30 \mathrm{~dB}$ to above $40 \mathrm{~dB}$ in the Swedish studies [2-4].

Although wind power has been harnessed as a source of electricity for several decades around the world, its rapid development in Poland is relatively recent. It is no wonder that data on reactions to the wind turbine noise in populated areas in Poland are missing. Thus, it has been attempted to evaluate the prevalence of perception of and annoyance due to the noise from wind turbines in people living in proximity to wind farms.

Similarly to the aforesaid European cross-sectional investigations, questionnaire surveys and predicted A-weighted SPLs, which were verified at random by in situ measurements, constituted the basis of this study. However, in order to assess the possible influence of mental health status on the noise-related annoyance, apart from the basic questionnaire (aimed at evaluation of annoyance due to the wind turbine noise) the respondents were additionally asked to complete the 12-item Goldberg General Health Questionnaire.

Please note that the respondents examined using GHQ-12 obtained a mean score at the level close to the normative result for the reference Polish population. Mental disorders were rather rare among the study subjects, since only $9.0 \%$ of them were recognized as "cases" compared to $27 \%$ in the healthy working population in Poland [6].

In this study, the calculated A-weighted SPL ranged from 30 to $48 \mathrm{~dB}$, while the measured A-weighted equivalent-continuous SPL remained within the range from 37 to $48 \mathrm{~dB}$. Over longer periods of time, the direction and speed of wind will vary and affect the actual SPL at the respondent's dwellings. Moreover, several unreliabilities related to the calculations might have led to an over- or underestimation of noise levels experienced in daily life. Nevertheless, there was a quite good agreement between the calculated and measured A-weighted SPLs since the mean value of difference was $0.7 \mathrm{~dB}$ (95\% CI: -2.6-1.2). 
As can be seen in Figure 1, the wind turbine noise prevailing at the respondents' dwellings included infrasonic components (the G-weighted equivalent-continuous SPL ranged from 61 to $90 \mathrm{~dB}$ at distance from $235 \mathrm{~m}$ to $2470 \mathrm{~m}$ ) but at the levels lower than the hearing threshold levels. These results were not surprising since all the wind turbines in this study were upwind devices [15]. Please note that recently, O'Neal et al. [16] performed noise surveys outside and inside residencies nearby wind turbines from 2 different manufactures and they also found that the measured (at distance of $305 \mathrm{~m}$ and $457 \mathrm{~m}$ ) sound pressure levels (in 1/3-octave bands) in the infrasonic range were lower than the hearing threshold levels.

In order to evaluate annoyance due to the noise from wind turbines, the participants of this study completed the questionnaire, which was based on the one previously used in the Swedish studies [2,3]. In order to reduce self-reporting survey bias, like that inherent to the aforesaid questionnaire, it also included questions about several potential environmental stressors and did not allow respondents to realize that the focus of the study was on the wind turbine noise. It is worth to underline that there was a high correspondence between the responses to the general questions concerning the noise from wind turbine at the beginning of the Swedish questionnaire and the more specific questions later (expressed by Cronbach's $\alpha$ coefficient equal to 0.885 ) [2]. In this study, statistical analysis also confirmed a high internal consistency of different questions evaluating response to wind turbines $(\alpha=0.93)$.

The Swedish and Dutch studies cited above showed that proportion of people perceiving and being annoyed by the wind turbine noise increased along with increasing A-weighted SPLs as shown by odds ratio (with $95 \%$ confidence intervals) greater than 1.0 [2-4]. It has been also found that subjects were more likely to be annoyed when A-weighted sound pressure levels exceeded $35-40 \mathrm{~dB}[3,4]$. Moreover, the wind turbine noise was found to be more annoying than transportation noise or industrial noise at comparable levels, possibly due to specific sound properties such as a "swishing" quality, temporal variability and lack of nighttime abatement [4]. Some personal factors (such as having turbines visible from the dwelling, negative opinion about wind turbines in general and/or their visual impact on landscape as well as self-reported sensitivity to noise) appeared to increase the odds of being annoyed by the wind turbine noise [2,3].

On the other hand, especially in the Dutch studies, the risk of annoyance was considerably lower in the subjects obtaining economic benefits from wind turbines [4]. Moreover, according to the aforesaid studies, perception and annoyance were associated with terrain and urbanization, i.e., i) a rural area increased the risk of perception and annoyance in comparison with a suburban area; and ii) in a rural setting, diversified (hilly or rocky) terrain increased the risk compared with a flat terrain [3].

Our pilot study included only the respondents living in the countryside or in small villages located in a rather flat and mainly agricultural terrain with low traffic intensity. Thus, we did not analyze the impact of terrain and urbanization on annoyance related to the wind turbine noise.

Nevertheless, the results of our pilot study are in line with some earlier observations from the Swedish and Dutch cross-sectional studies. In particular, we confirmed that odds ratio of being annoyed outdoors by the wind turbine noise increased along with increasing A-weighted sound (noise category) and subjective factors such as subjects' attitude to wind turbines in general (or to their visual impact) as well as sensitivity to landscape littering (or sensitivity to noise) had impact on perceived annoyance. Our findings were supported by the logistic multiple regression analysis. Various logistic models were created, including noise category and subjective factors as explanatory variables of variance in annoyance assessment.

It has been shown that only $7 \%$ of variance in annoyance could be explained by the noise, and the odds ratio that the respondents would be annoyed increased 2.1 
times from one to the next noise category $(\mathrm{OR}=2.10$; 95\% CI: 1.22-3.62). The highest value of the explained variance $(63.1 \%)$ was obtained for the model containing noise category, general attitude to wind turbines, sensitivity to landscape littering and mental health status (expressed in the GHQ-12 score) as explanatory variables. However, almost the same percentage of explained variance $(62.8 \%)$ was obtained while only noise category, general attitude to wind turbines and sensitivity to landscape littering were related to annoyance.

For comparison, in the Swedish study (that comprised people living in the rural sites with flat terrain), $13 \%$ of annoyance was explained by noise (OR $=1.87 ; 95 \%$ CI: 1.47-2.38). However, when the influence of noise was analyzed together with the attitude to visual impact, the percentage of explained variance in annoyance increased from $13 \%$ to $46 \%$. Taking into account 2 next subjective factors i.e., attitude to wind turbines and sensitivity to noise, did not improve the model as the influence of these 2 explanatory variables was not statistically significant [2].

Recently, of the basis of available data from 2 surveys in Sweden and 1 survey in the Netherlands, the exposure-response relationships between the exposure metric $\mathrm{L}_{\text {den }}$ (day-eveningnight noise level) and self-reported annoyance, indoors as well as outdoors of the dwellings, due to the wind turbine noise were determined using the method previously applied to derive the exposure-response relationships for transportation and industrial noise. In comparison to other sources of environmental noise, annoyance due to the wind turbine noise is found at relatively low noise exposure levels [17].

To compare the proportions of subjects annoyed by the wind turbine noise observed in this study with the predictions of the aforesaid exposure-response relationships, a correction was added to the predicted A-weighted SPLs in order to obtain the exposure metrics $\mathrm{L}_{\text {den }}$. A correction factor of $+4.7 \mathrm{~dB}$, calculated by van der Berg [10], was added to those data (Table 3). However, due to a small number of cases, the noise categories of 30-35 dB

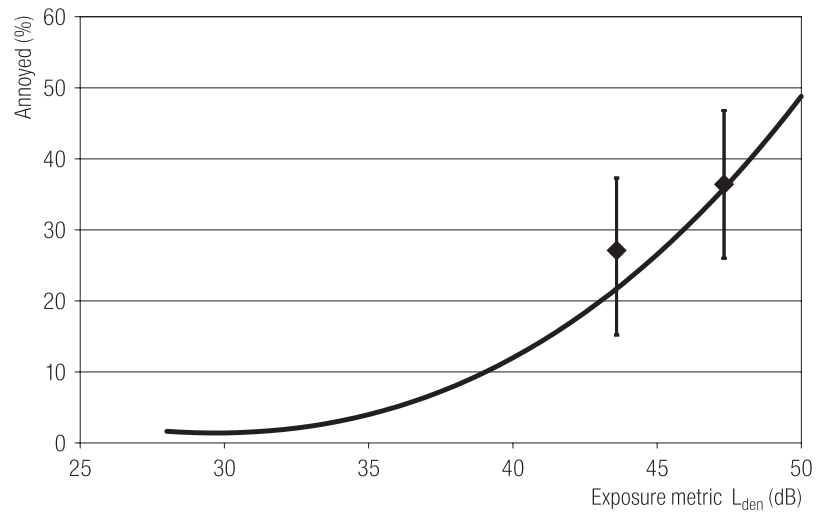

$\mathrm{L}_{\text {den }}$ - day-evening-night noise level.

Solid line represents exposure-response relationship for wind turbine annoyance outdoors (based on Janssen et al. [17]), rhombuses with whiskers represent observed in this study proportions (with $95 \%$ confidence levels) of respondents being annoyed outdoors by wind turbine noise.

Fig. 6. Proportion of respondents being annoyed outdoors by the wind turbine noise in comparison with proposed by Janssen et al. [17] exposure-response relationship for wind turbine annoyance outdoors

and $45-50 \mathrm{~dB}$ were not taken into account when analyzing the influence of noise level on proportion of the respondents who were annoyed by the wind turbine noise. As can be seen in Figure 6, the observed percentages of the respondents being annoyed outdoors by noise at given $\mathrm{L}_{\text {den }}$ levels fitted quite well to the proposed exposure-relationship for annoyance outdoors. Similar relationship was found when analyzing the perceived annoyance indoors (Figure 7). Further analysis of combined data from the aforesaid 3 cross-sectional studies showed that the subjects who were annoyed outdoors by the wind turbine noise were more likely to report sleep disturbances, felling tense and stressed and irritable [5]. On the other hand, it was found in this study that the respondents reporting annoyance outdoors were more likely to report difficulties with falling asleep. Moreover, they also reported dizziness and heartaches more frequently than those not annoyed outdoors. It is worth to underline that minimum setback distances have been established world-wide to reduce or avoid potential 


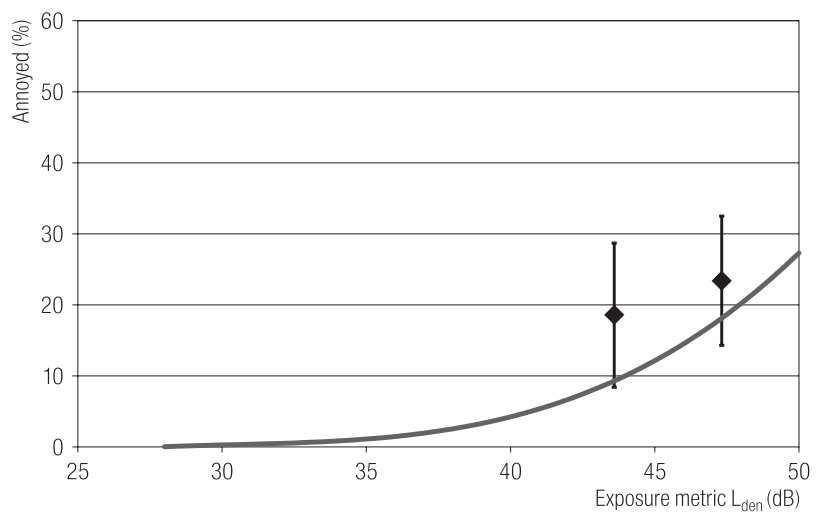

$\mathrm{L}_{\text {den }}$ - day-evening-night noise level.

Solid line represents exposure-response relationship for wind turbine annoyance indoors (based on Janssen et al. [17]), rhombuses with whiskers represent observed in this study proportions (with 95\% confidence intervals) of respondents being annoyed indoors by wind turbine noise.

Fig. 7. Proportion of the respondents being annoyed indoors by the wind turbine noise in comparison with proposed by Janssen et al. [17] exposure-response relationship for wind turbine annoyance indoors

noise complaints from, or potential effects to, people living in proximity to wind turbines. For example, in Ontario, a minimum setback distance of $550 \mathrm{~m}$ must exist between the centre of the base of the wind turbine and the nearest noise receptor (e.g., a building or campground). This minimum setback distance was developed through noise modeling under worst-case conditions to give a conservative estimate of the distance at which the noise attains a A-weighted sound level of $40 \mathrm{~dB}$ [18], the noise level that corresponds to the WHO night-noise guideline, a health-based limit [19].

According to our results, the greater distance from the nearest wind turbine, the smaller the percentage of respondents being annoyed outdoors by the wind turbine noise. In particular, proportions of the subjects annoyed by the wind turbine noise during various activities such as relaxing outdoors, get-together outdoors and taking walks decreased significantly from $24-31 \%$ at the distance category of $400-800 \mathrm{~m}$ to $5-7 \%$ at the distance category of 800-1200 m (see Table 5). However, at the distance category of $800-1200 \mathrm{~m}, 23.3 \%$ of the subjects generally perceived the wind turbine noise as annoying outdoors, while $14 \%$ of them - indoors. Nevertheless, taking into account significant decreasing of annoyance during the mentioned above activities in greater distances, the setback distance of at least 800-1200 m (approx. $1000 \mathrm{~m}$ ) seems to be sufficient to minimize the probability of being annoyed by the wind turbine noise and applicable in Poland.

To sum up, the results of our pilot study evaluating the perception of and annoyance due to the wind turbine noise in populated areas in Poland are in line with the observations from earlier Swedish and Dutch cross-sectional studies. Nevertheless, before firm conclusions can be drawn further studies are needed, including a larger number of respondents with different living environments (i.e., dissimilar terrain, different urbanization and road traffic intensity).

\section{CONCLUSIONS}

1. It has been shown that the wind turbine noise at the calculated A-weighted sound pressure level of 30-48 dB was perceived outdoors as annoying by a $1 / 3$ of all the respondents living in the vicinity of wind farms. Moreover, about $1 / 5$ of them were annoyed indoors.

2. The wind turbine noise was more frequently reported as annoying than other environmental nuisances, in particular other environmental noises.

3. The odds ratio of being annoyed outdoors by the wind turbine noise increased along with increasing A-weighted sound pressure level.

4. Irrespective of the noise level, subjective factors such as attitude towards wind turbines in general and sensitivity to landscape littering were found to significantly influence the perceived annoyance from the wind turbine noise. About $63 \%$ of variance in annoyance assessment outdoors might be explained by noise, general attitude to wind turbines and sensitivity to landscape littering.

5. Further studies are needed, including a larger number of respondents, before firm conclusions can be drawn. 


\section{REFERENCES}

1. Stansfeld SA, Matheson MP. Noise pollutions: Non-auditory effects on health. Br Med Bull. 2003;68:243-57, http:// dx.doi.org/10.1093/bmb/ldg033.

2. Pedersen E, Persson Waye K. Perception and annoyance due to wind turbine noise - A dose-response relationship. J Acoust Soc Am. 2004;116(6):3460-70, http://dx.doi. org/10.1121/1.1815091.

3. Pedersen E, Persson Waye K. Wind turbine noise, annoyance and self-reported health and well-being in different living environments. Occup Environ Med. 2007;64(7):480-6, http://dx.doi.org/10.1136/oem.2006.031039.

4. Pedersen E, van den Berg F, Bakker R, Bouma J. Response to noise from modern wind farms in the Netherlands. J Acoust Soc Am. 2009;126(2):634-43, http://dx.doi. org/10.1121/1.3160293.

5. Pedersen E. Health aspects associated with wind turbine noise - Results from three field studies. Noise Control Eng J. 2011;59(1):47-53, http://dx.doi.org/10.3397/1.3533898.

6. Makowska Z, Merecz D. [Polish adaptation of David Goldberg's General Health Questinnaires: GHQ-12 and GHQ-28]. In: Dudek B, editor. [Assessment of mental health status using David Goldberg's Questionnaires. Guide for users of GHQ-12 and GHQ-28]. Lódź: Nofer Institute of Occupational Medicine; 2001. Polish.

7. Makowska Z, Merecz D, Mościcka A, Kolasa W. The validity of General Health Questionnaires, GHQ-12 and GHQ-28, in mental health studies of working people. Int J Occup Med Environ Health. 2002;15(4):353-62.

8. ISO 9613-2:1996. Attenuation of sound during propagation outdoors. Part 2: General method of calculation. Geneva: International Organization for Standardization; 1996.

9. Geoportal.gov.pl [Internet]. Warszawa: Head Office of Geodesy and Cartography; 2012 [cited 2012 Aug 20]. Available from: http://www.geoportal.gov.pl.

10. van den Berg F. Criteria for wind farm noise: $\mathrm{L}_{\text {max }}$ and $\mathrm{L}_{\text {den }}$. Proceedings of the 7 th European Conference on
Noise Control, EURONOISE, Acoustics'08 Paris, 2008 Jun 29 - Jul 4; Paris, France [cited 2012 Aug 20]. Available from: http:/webistem.com/acoustics2008/acoustics2008/cd1/ data/index.html.

11. [The Decree by the Minister of Environment of November 4, 2008 on the requirements with respect to the measurements of emission levels and the measurements of the amounts of abstracted water. Journal of Laws 2008, No. 206, item 1291]. Polish.

12. Nagelkerke NJD. A note on the general definition of the coefficient of determination. Biometrika. 1991;78(3):691-2, http://dx.doi.org/10.1093/biomet/78.3.691.

13. ISO 226:2003. Acoustic. Normal equal-loudness contours. Geneva: International Organization for Standardization; 2003.

14. Leventhall G, Pelmear P, Benton S. A review of published research on low frequency noise and its effects. Department for Environment, Food and Rural Affairs. Defra Publications, London 2003 [cited 2012 Aug 20]. Available from: http://archive.defra.gov.uk/environment/quality/noise/research/lowfrequency/documents/lowfreqnoise.pdf.

15. Leventhall G. Infrasound from wind turbines - facts, fiction or deception. Can Acoust. 2006;34(2):29-34.

16. O'Neal RD, Hellweg Jr. RD, Lampeter RM. Low frequency noise and infrasound from wind turbines. Noise Control Eng J. 2011;59(2):135-57, http://dx.doi.org/10.3397/1.3549200.

17. Janssen SA, Vos H, Eisses AR, Pedersen E. A comparison between exposure-response relationships for wind turbine annoyance and annoyance due to other noise sources. J Acoust Soc Am. 2011;130(6):3746-53, http://dx.doi.org/ $10.1121 / 1.3653984$.

18. Knopper LD, Ollson CA. Health effects and wind turbines: A review of the literature. Environ Health. 2010. [cited 2012 Aug 20];10:78. Available from: http://www.ehjournal.net/ content/10/1/78.

19. World Health Organization Regional Office for Europe: Night Noise Guidelines for Europe. Copenhagen: WHO; 2009 [cited 2012 Aug 20]. Available from: http://www. euro.who.int/_data/assets/pdf_file/0017/43316/E92845.pdf.

This work is available in Open Access model and licensed under a Creative Commons Attribution-NonCommercial 3.0 Poland License - http://creativecommons.org/ licenses/by-nc/3.0/pl/deed.en. 